University of New Mexico

UNM Digital Repository

Mathematics and Statistics Faculty and Staff

Publications

Academic Department Resources

2013

\title{
Clan Capitalism, Graph Distance, and Other Issues
}

\author{
Florentin Smarandache \\ University of New Mexico, smarand@unm.edu \\ Victor Christianto \\ victorchristianto@gmail.com
}

Follow this and additional works at: https://digitalrepository.unm.edu/math_fsp

Part of the Business Administration, Management, and Operations Commons, Communication

Commons, Entrepreneurial and Small Business Operations Commons, Mathematics Commons, and the

Organizational Behavior and Theory Commons

\section{Recommended Citation}

Smarandache, Florentin and Victor Christianto. "Clan Capitalism, Graph Distance, and Other Issues." Kogaion Editions (2013). https://digitalrepository.unm.edu/math_fsp/279

This Book is brought to you for free and open access by the Academic Department Resources at UNM Digital Repository. It has been accepted for inclusion in Mathematics and Statistics Faculty and Staff Publications by an authorized administrator of UNM Digital Repository. For more information, please contact amywinter@unm.edu, Isloane@salud.unm.edu, sarahrk@unm.edu. 


\section{Clan Capitalism,}

Graph Distance,

and Qther Issues

A collection of social andleconomics papers

Florentin Smarandache \& V.Chris lanto, sciprint.org

\section{0 \\ KOGAION EDITIONS - 2013}




\section{Clan Capitalism, Graph \\ Distance, and Other Issues:}

A collection of social and economics papers

By Prof. Florentin Smarandache, Dept. of Mathematics and Science, University of New Mexico, Gallup, USA And V. Christianto, http://www.sciprint.org

2013

Kogaion Editions, Bucharest 
The cover image is taken from Neogeometrism, by Florentin Smarandache, Hexis - Phoenix, 2007, p.98

\section{KOGAÏON ÉDITIONS}

Division of CASA GROUP OF COMPANIES SRL

62, Scoala Herastrau street, code 014153

Bucharest - Romania, Europe

The readers can contact the authors via email at: fsmarandache@gmail.com or victorchristianto@gmail.com

Cover design and layout by V. Christianto

Copyright (C) Authors for their papers, 2010.

Copyright (C) Publication by Kogaion Editions, 2013.

Copyright note: Electronic copying, print copying and distribution of this book for noncommercial, academic or individual use can be made by any user without permission or charge. Any part of this book being cited or used howsoever in other publications must acknowledge this publication. No part of this book may be reproduced in any form whatsoever (including storage in any media) for commercial use without the prior permission of the copyright holder. Requests for permission to reproduce any part of this book for commercial use must be addressed to the Author. The Author retains his rights to use this book as a whole or any part of it in any other publications and in any way he sees fit. This Copyright Agreement shall remain valid even if the Author transfers copyright of the book to another party.

Many books can be downloaded from the following Digital Library of Science: http://www.gallup.unm.edu/ smarandache/eBooks-otherformats.htm

ISBN: 978-159-97321-5-2 


\title{
Clan Capitalism, Graph Distance, and Other Issues:
}

\author{
A collection of social and economics papers \\ By Florentin Smarandache \& V. Christianto
}

\begin{abstract}
This book consists of 6 papers focusing on social and economic issues. The topics covered include graph distance and optimal communication, migration in Jaipur, urbanization, clan capitalism, world population growth rate, and scientific inquiry. These papers were written in the period between 20092010.

Hopefully the readers will find some new insights in this collection of papers.
\end{abstract}




\section{COLLECTION OF SOCIAL AND ECONOMICS PAPERS}

by Florentin Smarandache and V. Christianto

\section{Contents}

1. F. Smarandache \& V. Christianto, Graph distance, optimal communication and group stability: a preliminary conjecture, (2009)

2. J. Singh, H. Yadav \& F. Smarandache, Structural dynamics of various cases of migration in Jaipur (2010)

3. J. Singh, H. Yadav \& F. Smarandache, District level analysis of urbanization from rural-to-urban migration in the Rajasthan State (2010)

4. V. Christianto, The emerging clan capitalism in the world (2010).

5. V. Christianto, A comment on world population growth rate and World 3 simulation (2010)

6. V. Christianto \& F. Smarandache, On the relation between mathematics, natural sciences and scientific inquiry (2009) 


\title{
Graph Distance, Optimal Communication and Group Stability: A Preliminary Conjecture
}

\author{
Florentin Smarandache (fsmarandache@yahoo.com) \\ University of New Mexico, Gallup, NM 87301, USA \\ V. Christianto (vxianto@yahoo.com) \\ Sciprint.org Administrator \\ Jakarta, Indonesia
}

\section{Introduction}

In recent years, there has been a rapid increase in the literature which discusses new phenomenon associated to social network. One of the well-known phenomenon in this regards is known as 'six degrees of separation' [1], which implies that one can always keep a communication with each other anywhere within a six-step. A number of experiments has verified this hypothesis, either in the context of offline communication (postal mail), or online communication (email, etc.).

In this article, we argue that by introducing this known 'six degrees of separation' into the context of group instability problem, one can find a new type of wisdom in organization. Therefore, we offer a new conjecture, which may be called 'Group stability conjectures based on Graph/Network distance."

To our knowledge this conjecture has not been discussed elsewhere, and therefore may be useful for further research, in particular in the area of organization development and group stability studies. The purpose of this article was of course not to draw a conclusive theory, but to suggest further study of this proposed conjecture.

\section{Graph Distance}

Let $G(V, E)$ be a graph, where $V$ is a set of vertices, and $E$ a set of edges:

$$
V=\left\{v_{1}, v_{2}, \ldots\right\}, E=\left\{e_{1}, e_{2}, \ldots\right\} .
$$

We say that there is a route between vertices $v_{i}$ and $v_{j}$. We define the distance between vertices $v_{i}$ and $v_{j}$, noted by $d\left(v_{i}, v_{j}\right)$ as the shortest chain of edges that connects $v_{i}$ with $v_{j}$.

In the graph $G(V, E)$ let's consider

$$
d\left(v_{i}, v_{j}\right)=n \geq 1
$$

where $n$ is the number of edges connecting $v_{i}$ with $v_{j}$, and for each such edge an equiprobability

$$
\frac{1}{n} \text {. }
$$

Using Shannon's entropy 


$$
H(x)=-\sum_{i=1}^{n} P_{i} \log _{2}\left(P_{i}\right)
$$

In order to find the entropy of the distance between two vertices we get

$$
H\left(d\left(v_{i}, v_{j}\right)\right)=-\sum_{i=1}^{n} P_{i} \log _{2}\left(P_{i}\right)=-\sum_{i=1}^{n} \frac{1}{n} \log _{2}\left(P_{i}\right)=-\log _{2}\left(\frac{1}{n}\right)=\log _{2} n,
$$

since all $P_{i}=\frac{1}{n}$.

The longer is the distance between two vertices, the bigger is the entropy, since $\log _{2} n_{1}>\log _{2} n_{2}$ when $n_{1}>n_{2} \geq 1$, therefore the more degree of disorder, of loss of information, as both ambiguity and imprecision increase.

\section{A Conjecture of Group Stability Based on Graph Distance}

A hierarchical structure is a widespread organization form in many areas.

The hidden assumption behind Small-world hypothesis is that everyone is around six-steps away from any other person on Earth, which is known as 'six degrees of separation' principle. A number of experiments have been conducted in order to prove this hypothesis. [2]

In this regards, apparently we can draw analogy from this 'six degrees of separation' to the concept of graph distance. In this context, graph distance can be viewed as the number of 'nodes' that one should reach to come to a destination. This study of graph distance and group stability is quite new, and only a number of published articles have appeared in journals, see for example [3], [4].

Once this analogy is set, it becomes apparent that the 'six degrees of separation' may be interpreted as an optimum graph distance, where any given organization can function in its best, provided we can consider an organization as an actual social-network which functions better if and only if communication can be preserved in optimal way.

In other words, any given organization which expands rapidly beyond these six-degrees of node separation (let say, between the CEO and its factory workers) will be more prone to instability. This phenomenon may also be viewed as another example of 'self-organized criticality' process in any given organization/structure.

At this point, now we will write down our new conjecture of Group stability based on Graph distance:

(a) For a given organization in any industry, there is an optimal graph distance which will keep communication in organization in its optimum. We can call this as 'optimal graph distance number'.

(b) This optimal graph distance number is inversely proportional to the innovation cycle time in any given organization. This optimal graph distance corresponds to both the hierarchy of organization and also to the degrees of separation.

(c) There is tendency that any organization will increase its size such that the graph distance number always grows such that it exceeds its own level of incompetence (similar to Lawrence's principle). 
(d) In order to keep internal and healthy communication for its own survival preservation, a good organization will keep its graph distance number at optimal level.

(e) If an organization has graph distance number which exceeds its optimal number (let say 5 or 6 degrees of separation), then it will be prone to instability.

(f) Group instability can take the form of de-formation of organization in order to meet the communication works again, in other words an organization has tendency to keep the graph distance number at optimal, in accordance with self-organized criticality phenomena.

(g) This is what can be called as Conjecture of Group Stability based on Graph Distance.

While the above conjecture may appear quite simple and obvious at first sight, it covers the phenomena corresponding to group stability in uniquer way, i.e. from the viewpoint of preservation of optimum communication. Therefore any organization has its own tendency to keep the size of its hierarchy such that the graph distance is kept optimal.

Let us mention a simple example here: Toyota has a unique management way, which is well-known in management literature. What is not quite well-studied is perhaps the fact that it has less hierarchical structure compared to other large automobile companies in USA. As a result, the innovation cycle time tends to be faster. For instance, Toyota has released its first generation of hybrid car (Prius) in 2007, while GM only expects to release a first version of hybrid cars by 2010. The simple lesson here (see point $b$ ) is that keep graph distance at minimum in order to reach faster innovation cycle.

The same lesson we often hear when an organization performs excellently in the past when its hierarchy remains small, but during the course of its history it tends to increase in 'graph distance' and then gradually it loses its 'agility'. In this regards one can observe that group stability has deep link with cooperation level in any given organization, because in large organization there is strong tendency that coordination becomes very difficult [4]. From the viewpoint of game theory, it becomes very difficult to maintain the condition such that all of its members have optimal return [3].

In turn, a good communication in organization can be viewed as part of 'social capital', which can play significant role to keep its stability. This viewpoint has been discussed in [5].

Similarly, a city which becomes too large and exceeds its capacity to maintain good communication tends to form smaller-cities (just like sub-urbans areas) in order to keep its optimal size.

In our opinion this conjecture has not been discussed elsewhere.

\section{References:}

[1] Curtis, A.R., "Small worlds: beyond social networking," http://rose-

hulman.edu/mathjournal/archives/2004/vol5-n2/paper7/v5n23-7pd.pdf. See also wikipedia entry on

'Six degrees of separation.'

[2] Adamic, L.A., \& Adar, E., "How to search a social network," http://www.cond.org/socsearch.pdf

[3] Currarini, S., "Group stability of hierarchies in games with spillovers," Math. Soc. Sciences Vol. 54 (3) (2007) 187-202.

[4] Demange, G., "On group stability in hiearrchies and network," J. Pol. Econ. 112(4) (2004) 754778. http://www.pse.ens.fr/demange/hieranet.pdf (One of early study on group stability). 
[5] Talmud, I., \& G. Mesch, "Market embeddedness and corporate instability," Social Science Research 26 (1997) p. 419-447.

First draft, 1 Apr. 2009; Second draft, 3 March 2010. 


\title{
STRUCTURAL DYNAMICS OF VARIOUS CAUSES
}

\author{
OF MIGRATION IN JAIPUR
}

Dr. Jayant Singh, Assistant Professor, Department of Statistics, University of Rajasthan, Jaipur, India

E-mail: jayantsingh47@rediffmail.com

\author{
Hansraj Yadav, Research Scholar, Department of Statistics, \\ University of Rajasthan, Jaipur, India \\ E-mail: hansraj_yadav@rediff.com
}

Dr. Florentin Smarandache, Chair of Math \& Sciences Department, University of New Mexico, Gallup, USA

E-mail: smarand@unm.edu 


Abstract
Jaipur urban area has grown tremendously in last three decades. Composition
of People migrating due to various reasons has display a meticulous trend.
Dominance of people moving due to marriages is getting sturdy whereas
Jaipur city is losing its luster in attracting persons for education and business.
Short duration migration from Jaipur district to urban area has gone down to a
very low level. Flow of migrants from Rural areas to Jaipur outpaced the
migrants from urban areas and its composition from various in terms long and
short distances migration has substantially changed over two consecutive
decades. Movements of males and females were differ on many criterion as
male moving faster than females for employment \& education and females
move faster than male for marriages and moving along family was found
evident in short, medium and long distances migration. Gender gap in people
migration from different reasons was observed and a gender specific trend
was seen favour. Short duration migration and migration due to education \&
employment is not as prominence as it was two decade back

INTRODUCTION: 
Migration from one area to another in search of improved livelihoods is a key feature of human history. While some regions and sectors fall behind in their capacity to support populations, others move ahead and people migrate to access these emerging opportunities. There are various causes like political, cultural, social, personal and natural forces but aspire for betterment, higher earning, more employment opportunities receive special attention. There are four type of migration namely
i. Rural-Rural
ii. Rural-Urban
iii. Urban- Urban
iv. Urban-Rural

Though all of these have different implication over the various demographic and socio-economic characteristics of the society but ruralurban \& urban-urban migration is a cause of concern in reference to migration process to Jaipur urban agglomeration. The dynamics of migration for three census $(1981,1991,2001)$ has been analyzed from different angles at destination i.e. Jaipur Urban Agglomeration. The peoples of two places have different socio-economic character like education attainment, availability of land to the rural labor and agriculture production capacity, industrialization etc and the difference of these factors at two places gear the migration process. 
Distance plays a prominent role in migration of peoples, in general people from nearby area show a faster pace than the distant places due to psychic of being come back or feel like at home or the reason that some acquaintance in nearby area plays a big pull factor. However these assumptions do govern by other consideration of pull and push factor and the prevalent socio-economic aspects of the origin and destination places.

Jaipur being the capital of the state and proximity to the national state has been a great potential to draw peoples. It has not been attracting peoples from the nearby areas but it has influence on the persons of entire state and other states of the country. Majority of immigrants to Jaipur belongs to different parts of the states followed by its adjoining states. However it has been able to attract people from all over the country and overseas as well though their contribution in totality is not as significant. Seeing at this scenario it is worthwhile to limit the migrants from the following area to comprehend the migrant process of Jaipur. In-migrants to Jaipur urban area from (a) various parts of Jaipur district (b) other districts of the state (c) adjoining states of the state having fair share in migrants and (d) total migration which is overall migration from all the areas.

\section{COMPOSITION OF IN-MIGRANTS TO JAIPUR:}


In-migrants to Jaipur has grown by leaps and bounds in the last three decades. The decadal growth of in-migrants to Jaipur in last four decades synchronized with the growth of urban population of the Jaipur. Though the decadal rate of growth of migrants is lagging behind to the growth of the urban population as both has been $59.3 \%$ \& $45.2 \%$ in decade $1991-2001,49.5 \%$ \& $35.8 \%$ in decade $1991-81$ respectively. Short Distance migration is considered, people from the other parts of Jaipur district who are coming to jaipur urban area, migration from other parts of the state is relatively longer distance migration and put in the moderate (medium) distance migration whereas the people from out side the state are in the category of long distance migration. The contribution of the short distance migration in total migration as per census of 2001, it was $17.1 \%$ against the $51 \%$ were medium distant migrants as they came from other districts of the state and long distance migration from some most contributing states namely Punjab, U. P., \& Delhi have there share as $9.6 \%, 3.3 \%$ \& $2.3 \%$ in total migrants to Jaipur in this same duration. These three states accounted for half of the long distance migration.

These different types of migration spell a meticulous trend over the years. As small distance migration shows a downward trend as its share in total migration which was $28.8 \%$ in yr 1981 came to $25.8 \%$ in according to census of 1991 and further slipped to $17.1 \%$ in census 2001 . Medium distance migration exhibited a opposite path to the short distance 
migration as it advanced to $47 \%$ in yr 1991 against $45 \%$ in yr 1981 which further ascended to $51 \%$ in $\mathrm{yr}$ 2001. Contribution of long distance migration in total migration from all states also exhibited rolling down trend. This trend followed suite for the migration from the adjoining states.

\section{COMPOSITIONAL DYNAMICS OF REASON FOR MIGRATION TO JAIPUR}

\section{URBAN AREA:}

Affect of various reasons of migration on peoples of diverse areas is different. Some reasons are more common than others moreover their affect on male and females is also different. Share of Rural and Urban inmigrants population will widely vary for various cause of migration. Distance of place of origin is also a crucial factor in migration process to any area. Dynamics of various reasons for migration will be analyzed from four perspectives.

1. Dominance of various reasons for migration;

2. Rural-Urban Paradigm and changes taking place;

3. Gender issues and disparity. 
DOMINANCE OF VARIOUS REASONS FOR MIGRATION IN MIGRATION PROCESS:

Person do migrate from a variety of reasons, prominent of them are migration due to 1 . Employment 2 . Education 3 . Marriage 4. Moving with family. Marriage has been the foremost reason for migration as its share in total migrants to Jaipur was $32.1 \%$ in yr 2001. People migrating for the employment and/or business with $27.3 \%$ contribution in total migration seconded the marriage cause. It was distantly followed by category of persons moving with family with $17.6 \%$ share in total migration. There was a remarkable difference in two dominating categories of people moving due to employment and marriage and it was that the people migrating to Jaipur due to employment is on declining side as it came down to $25 \%$ in yr 2001 from $27.3 \%$ in $\mathrm{yr} 1991$ and $30.2 \%$ in yr 1981 contrary to a gradual increase in people migrating to Jaipur because of marriage as it raised to $32.1 \%$ in $\mathrm{yr} 2001$ from $27.8 \%$ in $\mathrm{yr}$ 1991 and $25.2 \%$ in yr 1981.

Education as a cause of migration doesn't have significant contribution in total migration to Jaipur and it is getting meager over the years. As in yr 1981 its share in total migration was $6.1 \%$ and the figure came to $4.4 \%$ in $\mathrm{yr} 1991$ and further dip to $2.7 \%$ in $\mathrm{yr} 2001$. This movement is also followed by migrants for education from all the adjoining 
state, within state and from Jaipur district to Jaipur urban area. People moving with household also followed the decline suite though the rate of decline was steeper than the others as the share of people migrating under this category which was $30.2 \%$ in yr 1981 fall to $28.5 \%$ in yr 1991 and further it slip to $17.6 \%$ in yr 2001. Composition of various reasons for migration over last three decades is depicted in coming Graph.

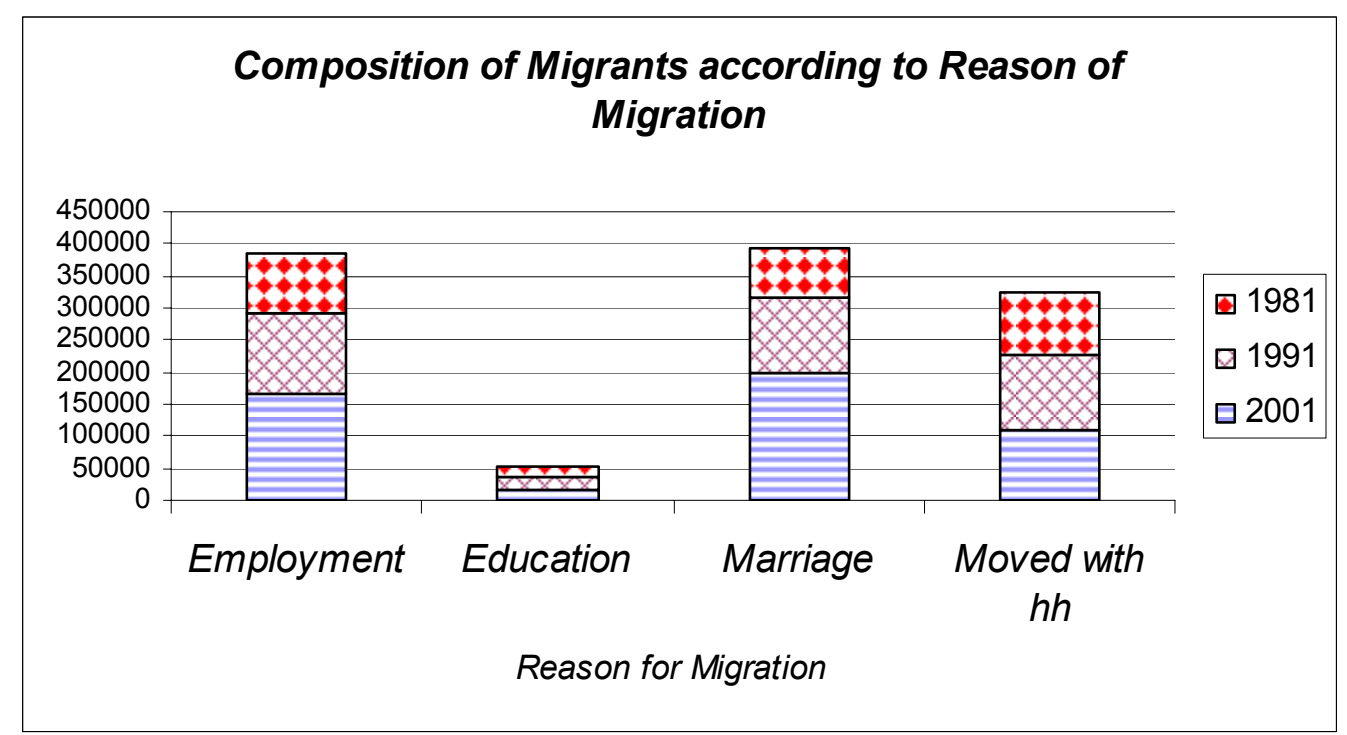

\section{RURAL-URBAN PARADIGM:}

Intensity of migration widely differs for persons migrating form Rural and Urban areas for various reasons for migration. Flow of migrants from Rural areas to Jaipur outpaced the migrants from urban areas. According to data of census in yr 1981, the share of migrants to Jaipur urban area from rural and urban areas was $53 \%$ \& $47 \%$ respectively and this gap 
remained intact in the coming decades. The trend in rural, urban and combined for last three decades is depicted in graph on next page.

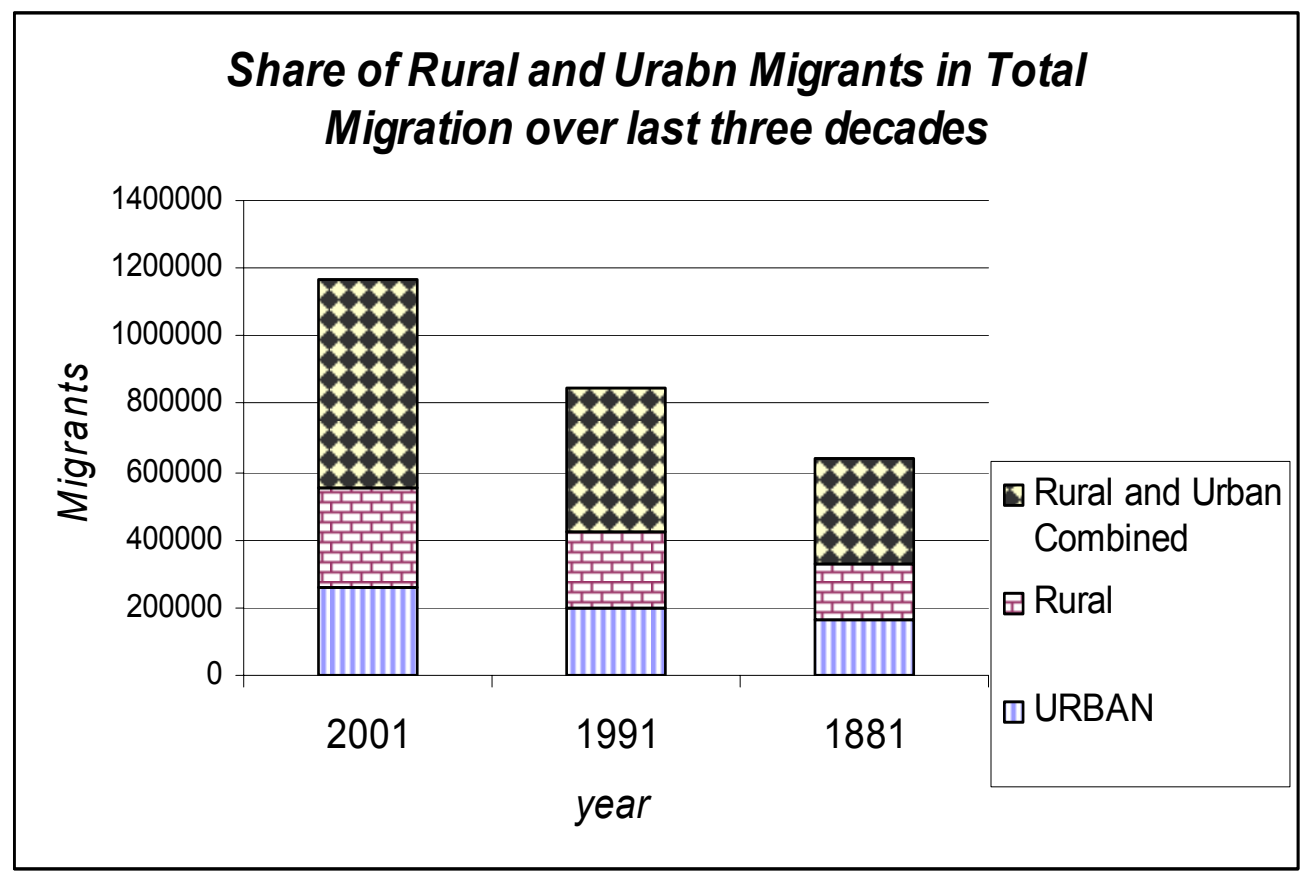

The contribution of rural \& urban migrants within a category of reason for migration over last two consecutive decades is tested by calculating the zvalues for various category of reason for migration for Rural \& Urban areas and significance was tested at $5 \%$ level of significance. To test the equality of share of Rural/Urban migrants from any reason of migration over a decade period following hypothesis was set up.

$\mathrm{H}_{0}$ : Share of Rural (or Urban) migrants due to any reason of migration in a decade is equal. $\left(p_{1}=p_{2}\right)$

Against

$$
H_{1}: p_{1} \neq p_{2}
$$


This is tested for two decadal period 1981-9991 \& 1991-2001.

$Z=\frac{p_{1}-p_{2}}{\sqrt{P Q}\left(\left(1 / n_{1}\right)+\left(1 / n_{2}\right)\right)}$
where $P=\frac{n_{1} p_{1}+n_{2} p_{2}}{n_{1}+n_{2}}$$\quad$ and $Q=1-P$

$p_{1}$ is the share of rural/urban migrants due to any reason at a point of time in total migration,

$\mathrm{p}_{2}$ is the share of rural/urban migrants due to that reason after a decade in total migration

To test this hypothesis, Z-value for equality of proportions of migrants from any reason over a decade is calculated and compared with tabulated value at $5 \%$ level of significance for the period 1981-9991 \& 1991-2001 for rural and urban migrants separately. Four groups according to share of migrants from any reason of migration over a decade period are formed to analyze the Rural-Urban dynamics of the migrant process.

Group1: Share of migrants from any reason of migration from Rural/Urban area over a decade period (in 1981-991 \& 1991-2001) is not 
equal. Means share of peoples migrating from rural \& urban areas for a particular reason of migration differ significantly over the period 1981-991 \& 1991-2001. Areas falling under this group shows a change in similar direction (i. e. share of urban \& rural migrants for that reason of migration has changed considerably over a decade period) for Rural \& Urban migrants in terms of their share in total migration for that reason of migration over a decade period.

Group 2: Share of migrants from any reason of migration from Rural/Urban area over a decade period (in 1981-991 \& 1991-2001) is equal. Means share of peoples migrating from rural \& urban areas for a particular reason of migration don't differ significantly over the period 1981-991 \& 1991-2001. Areas falling under this group don't shows any change (i. e. share of urban \& rural migrants for that reason of migration is has not changed over a decade period) for Rural \& Urban migrants in terms of their share in total migration for that reason of migration over a decade period.

Group 3: Share of migrants from any reason of migration from Rural area is not equal whereas for migrants from urban areas due to this reason is equal over a decade period (in 1981-991 \& 1991-2001). Means share of peoples migrating from Rural areas for a reason of migration differ significantly whereas share of peoples migrating from Urban areas 
for this reason of migration don't differ significantly over the period 1981$991 \& 1991-2001$. Areas falling under this group shows different story as share of Urban migrants for any reason of migration in total migration is not equal though for Rural Migrants it is equal over a decade period.

Group 4: Share of migrants from any reason of migration from Urban area is not equal whereas for migrants from Rural areas due to this reason is equal over a decade period (in 1981-991 \& 1991-2001). Means share of peoples migrating from Urban areas for a reason of migration differ significantly whereas share of peoples migrating from Rural areas for this reason of migration don't differ significantly over the period 1981991 \& 1991-2001. Areas falling under this group shows different story as share of Rural migrants for any reason of migration in total migration is not equal though for Urban Migrants it is equal over a decade period.

In Group 1 \& 2, migration due to any reason from rural and urban areas is in agreement i.e. share of migrants due to any reason over a decade either is significant or insignificant for both rural and urban migrants. In contrary to this In Group 3 \& 4, migration due to any reason from rural and urban areas is not in agreement i.e. share of migrants due to any reason over a decade is significant for urban migrants than it is insignificant for rural migrants or vice-versa. 
Z-value for testing hypothesis at $5 \%$ level of significance in a group will be as under.

Group 1: $Z_{u} \& Z_{r}>1.96$

Group 2: $Z_{\mathrm{u}} \& Z_{\mathrm{r}}<1.96$

Group 3: $Z_{\mathrm{u}}>1.96 \& Z_{\mathrm{r}}<1.96$

Group 4: $Z_{\mathrm{u}}<1.96 \& Z_{\mathrm{r}}>1.96$

Where $Z_{u}$ and $Z_{r}$ is the calculated value of $Z$ for migrants due to $a$ reason from Urban \& Rural area. The significance of Null hypothesis for all the groups is summarized in table on ensuing page. 


\begin{tabular}{|c|c|c|c|c|c|}
\hline \multirow[t]{3}{*}{\begin{tabular}{|l} 
Reason for \\
Migration
\end{tabular}} & \multicolumn{5}{|c|}{$\begin{array}{l}\text { Contribution of Rural \& Urban Migrants over a decade period } \\
\text { is in agreement for any reason of Migration }\end{array}$} \\
\hline & \multicolumn{3}{|c|}{ Duration 1991-2001 } & \multicolumn{2}{|c|}{ Duration 1981-1991 } \\
\hline & \multicolumn{2}{|c|}{$Z_{u} \& Z_{r}>1.96$} & 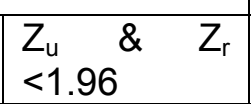 & $Z_{u} \& Z_{r}>1.96$ & $\begin{array}{l}Z_{u} \& Z \\
<1.96\end{array}$ \\
\hline Employment & \multicolumn{2}{|c|}{$\begin{array}{l}\text { Total Migration, } \\
\text { Elsewhere Jaipur } \\
\text { District, Gujrat }\end{array}$} & $\begin{array}{l}\text { Haryana, } \\
\text { U.P., Delhi }\end{array}$ & $\begin{array}{l}\text { Total Migration, } \\
\text { Elsewhere in } \\
\text { Jaipur District, in } \\
\text { other Districts, } \\
\text { Gujarat, } \\
\text { Hrayana, U.P., } \\
\text { Punjab, Delhi }\end{array}$ & \\
\hline Education & \multicolumn{2}{|c|}{$\begin{array}{l}\text { Total Migration, } \\
\text { Punjab }\end{array}$} & $\begin{array}{l}\text { Gujarat, } \\
\text { Haryana, } \\
\text { U.P., Delhi }\end{array}$ & -do- & \\
\hline Marriage & \multicolumn{2}{|c|}{$\begin{array}{l}\text { U.P., Punjab, } \\
\text { Haryana, Delhi }\end{array}$} & & $\begin{array}{l}\text { Elsewhere in } \\
\text { Jaipur District, in } \\
\text { other Districts, } \\
\text { Gujarat, } \\
\text { Hrayana, U.P., } \\
\text { Punjab, Delhi }\end{array}$ & \\
\hline $\begin{array}{l}\text { Moved with } \\
\text { Family }\end{array}$ & \multicolumn{2}{|c|}{$\begin{array}{l}\text { Total Migration, } \\
\text { Elsewhere in } \\
\text { Jaipur District, in } \\
\text { other Districts, } \\
\text { U.P., Punjab, } \\
\text { Delhi }\end{array}$} & & $\begin{array}{l}\text { Total Migration, } \\
\text { Elsewhere in } \\
\text { Jaipur District, in } \\
\text { other Districts, } \\
\text { Gujarat, } \\
\text { Hrayana, U.P., } \\
\text { Punjab, Delhi }\end{array}$ & \\
\hline \multirow[t]{3}{*}{$\begin{array}{l}\text { Reason for } \\
\text { Migration }\end{array}$} & \multicolumn{5}{|c|}{$\begin{array}{l}\text { Contribution of Rural \& Urban Migrants over a decade period } \\
\text { is not agreement for any reason of Migration }\end{array}$} \\
\hline & \multicolumn{3}{|c|}{ Duration 1991-2001 } & \multicolumn{2}{|c|}{ Duration 1981-1991 } \\
\hline & $\begin{array}{l}Z_{u}>1.96 \\
\& Z_{r}<1.96\end{array}$ & $Z_{u}<1$ & $96 \& Z_{r}>1.96$ & $\begin{array}{l}Z_{u}>1.96 \& Z_{r} \\
<1.96\end{array}$ & $\begin{array}{l}Z_{u} \\
<1.96 \\
\& Z_{r} \\
>1.96\end{array}$ \\
\hline Employment & & $\begin{array}{l}\text { in ot } \\
\text { Punjal }\end{array}$ & her Districts, & & \\
\hline Education & & $\begin{array}{l}\text { Elsew } \\
\text { Distric } \\
\text { Distric }\end{array}$ & $\begin{array}{l}\text { eere in Jaipur } \\
t, \quad \text { in other } \\
\text { ts, }\end{array}$ & & \\
\hline Marriage & Gujarat & & & Total Migration & \\
\hline $\begin{array}{l}\text { Moved with } \\
\text { Family }\end{array}$ & Haryana & & & & \\
\hline
\end{tabular}


It is apparent from this summarization that share of rural \& urban migrants in the period $1981 \& 1991$ differ widely for migrants coming from various places. Especially for migrants coming from other states the share of rural \& urban population in yr 1981 \& 1991 differ significantly for all the four categories of reason for migration. However this fact was a little bit different in the period of $1991-2001$ as migrants coming for education \& employment from rural \& urban areas of various states don't differ significantly in terms of their share in year 1991 \& 2001 in total migration.

Migrants from rural \& urban areas due to marriage, employment \& education were not in agreement as from some of the areas the proportion of rural migrants in year 1991 \& 2001 was significant whereas for urban it was not. Therefore for the duration 1991-2001 migrants from some of the places are not making significant difference in terms of their contribution for some of the reasons to migrate or for rural migrants it is not significant whereas for urban migrants it is significant or vice-versa. This situation was missing in the duration 1981-9991.

\section{GENDER ISSUES AND DISPARITY:}

Flow of male and female migration governed by different reasons differently and exhibit a different trait over the years. Looking at total in- 
migration in Jaipur it is found that contribution of males were phenomenal high in the category of people migrating due to employment and education as against the share of female was higher than males in category of persons migrating due to marriages and moving with family. Moreover the fact of male moving faster than females for employment \& education and females move faster than male for marriages and moving along family was also evident in short, medium and long distances migration and this gap at the segregated levels was much explicit than the aggregated level. Following hypothesis was formulated to test the gender disparity in migration.

$\mathrm{H}_{0}$ : Share of males (or females) migrants due to any reason for migration in a decade is equal (i.e. $\left.p_{1}=p_{2}\right)$

Against

$$
\mathrm{H}_{1}: \mathrm{p}_{1} \neq \mathrm{p}_{2}
$$

Formula for $Z$ remain same whereas $p_{1}$ is the share of male/female migrants due to any reason at a point of time in total migration and $p_{2}$ is the share of male/female migrants due to that reason after a decade in total migration.

To test this hypothesis Z-value for equality of proportions of migrants from any reason over a decade is calculated and compared with tabulated value at $5 \%$ level of significance for the period $1981-9991 \&$ 
1991-2001 for male and female migrants separately. Four groups according to share of migrants of any reason for migrations over a decade period are formed to analyze the Rural-Urban dynamics of the migrant process.

Z-value for testing hypothesis at $5 \%$ level of significance for the four groups will be as under.

Group 1: $Z_{m} \& Z_{f}>1.96$

Group 2: $Z_{m} \& Z_{f}<1.96$

Group 3: $Z_{m}>1.96 \& Z_{f}<1.96$

Group 4: $Z_{m}<1.96 \& Z_{f}>1.96$

Where $Z_{m}$ and $Z_{f}$ is the calculated value of $Z$ for male \& female migrants due to a reason. The significance of Null hypothesis for all the groups is summarized in table inserted below. 


\begin{tabular}{|c|c|c|c|c|}
\hline \multirow[t]{3}{*}{$\begin{array}{l}\text { Reason for } \\
\text { Migration }\end{array}$} & \multicolumn{4}{|c|}{$\begin{array}{l}\text { Contribution of Male \& Female Migrants over a decade period is in } \\
\text { agreement for any reason of Migration }\end{array}$} \\
\hline & \multicolumn{2}{|c|}{ Duration 1991-2001 } & \multicolumn{2}{|l|}{ Duration 1981-1991 } \\
\hline & $Z_{m} \& Z_{f}>1.96$ & $Z_{m} \& Z_{f}<1.96$ & $Z_{m} \& Z_{f}>1.96$ & $Z_{m} \& Z_{f}<1.96$ \\
\hline Employment & $\begin{array}{l}\text { Total Migration, } \\
\text { in other } \\
\text { Districts }\end{array}$ & $\begin{array}{l}\text { Gujarat, } \\
\text { Punjab, } \\
\text { Haryana, } \\
\text { U.P., Delhi }\end{array}$ & $\begin{array}{l}\text { Total Migration, in } \\
\text { other Districts, } \\
\text { Gujarat, Punjab, }\end{array}$ & \\
\hline Education & & $\begin{array}{l}\text { Gujarat, } \\
\text { Punjab, } \\
\text { Haryana, } \\
\text { U.P., Delhi }\end{array}$ & Total Migration & $\begin{array}{l}\text { Gujarat, } \\
\text { Punjab, } \\
\text { Haryana, } \\
\text { U.P., Delhi }\end{array}$ \\
\hline Marriage & $\begin{array}{l}\text { Total } \\
\text { Migration, }\end{array}$ & & $\begin{array}{l}\text { Total Migration, } \\
\text { Elsewhere in } \\
\text { Jaipur District, in } \\
\text { other Districts, } \\
\text { Haryana, Punjab, }\end{array}$ & \\
\hline $\begin{array}{l}\text { Moved with } \\
\text { Family }\end{array}$ & $\begin{array}{l}\text { Total } \\
\text { Migration, } \\
\text { Elsewhere in } \\
\text { Jaipur District }\end{array}$ & & $\begin{array}{l}\text { Total Migration, } \\
\text { Elsewhere in } \\
\text { Jaipur District, in } \\
\text { other Districts, } \\
\text { Gujarat, U.P, Delhi }\end{array}$ & \\
\hline \multirow[t]{3}{*}{$\begin{array}{l}\text { Reason for } \\
\text { Migration }\end{array}$} & \multicolumn{4}{|c|}{$\begin{array}{l}\text { Contribution of Male \& Female Migrants over a decade period is } \\
\text { not in agreement for any reason of Migration }\end{array}$} \\
\hline & Duration 1991-2 & 001 & Duration $1981-19$ & \\
\hline & $\begin{array}{l}Z_{m}>1.96 \& Z_{f} \\
<1.96\end{array}$ & $\begin{array}{l}Z_{m}<1.96 \& Z_{f} \\
>1.96\end{array}$ & $\begin{array}{l}Z_{m}>1.96 \& Z_{f} \\
<1.96\end{array}$ & $\begin{aligned} Z_{m} & <1.96 \& \\
Z_{f} & >1.96\end{aligned}$ \\
\hline Employment & $\begin{array}{l}\text { Elsewhere in } \\
\text { Jaipur District } \\
\text { in other districts }\end{array}$ & & $\begin{array}{l}\text { Gujarat, Punjab, } \\
\text { Haryana, U.P., } \\
\text { Delhi }\end{array}$ & \\
\hline Education & $\begin{array}{l}\text { Total } \\
\text { Migration, in } \\
\text { other Districts }\end{array}$ & & $\begin{array}{l}\text { Elsewhere in } \\
\text { Jaipur District, in } \\
\text { other Districts }\end{array}$ & \\
\hline Marriage & & $\begin{array}{l}\text { Elsewhere in } \\
\text { Jaipur } \\
\text { District, in } \\
\text { other Districts } \\
\text { Gujarat, } \\
\text { Punjab, } \\
\text { Haryana, } \\
\text { U.P., Delhi }\end{array}$ & & Gujarat \\
\hline $\begin{array}{l}\text { Moved with } \\
\text { Family }\end{array}$ & & $\begin{array}{l}\text { in other Districts } \\
\text { Gujarat, Punjab, } \\
\text { Haryana, U.P., } \\
\text { Delhi }\end{array}$ & & $\begin{array}{l}\text { Punjab, } \\
\text { Haryana, } \\
\text { U.P., Delhi }\end{array}$ \\
\hline
\end{tabular}


It is evident from the above results that the contribution of male and females in different categories over two decades (1981-91 \& 1991-2001) has changed considerably and the disparity is widened. As most of the categories in duration (1981-1991) fall in the group where both $Z_{m}$ \& $Z_{f}>1.96$ which means proportion of the males \& females over a decade was significantly different. In this way male \& females for most of the categories were in agreement $\left(Z_{m} \& Z_{f}>1.96\right)$ as both were significant as far as their contribution in total migration over a decade is concerned. Except for the people moving due to education from other states as $Z_{m}$ \& $Z_{f}<1.96$ for this category. This means that share male \& females migrating due to education from other states in total migration in the year 1981 \& 1991 was same and this remained stabilized in year 2001. People migrating due to marriages \& moving with family also showed a change in this three decade period as migrating from most of the areas in year 1991 over 1981 exhibited that the share was considerably changed $\left(Z_{m} \&\right.$ $\left.Z_{f}>1.96\right)$ whereas in year 2001 over 1991 it showed that it has not changed for males though for females it has changed. Thus people moving under these categories have shown a shift in term of increasing share toward females.

Migrants from different areas exhibit a considerable shift in terms of contribution of males or females in total migration over a period of ten years. However overall migrants say that three categories (employment, 
marriage \& moved with family) followed the same suite as the share of male \& female was significant for testing hypothesis for equality of the same over the duration 1981-991 \& 1991-2001.

\section{Summary:}

Contribution of people migrating for education in total migration is on a steep declining as its contribution in total migration has decreased by one third over a two decade period. People migrating due to marriage is showing a phenomenal incremental growth \& it is supposed to grow with a faster pace due to decline sex ratio in the city. Migration due to education is having less contribution in total migration and it is going thinner over the years because of education facilities in smaller town and easy accessibility to them in small town. Therefore no longer education is as significant for tempting to migrate as it used to be two decades back. In the coming years this cause of migration will further tend to lose its impact in overall mobility of peoples. People migrating with family is also on a downward trend as people moving with family and due to marriage are together constitute inactive movement as people are not necessarily moving by choice or primarily don't have motive of employment, business or education which itself are related to betterment of life/career. 
The share of inactive movements in total migration has came down by $5 \%$ over a decade. If this trend continues and the economic progress of the Jaipur indicates that it will attract the people for economic reasons than the share of migrants in working population will grow which in turns contribute for the economy of the City as the share of people moving with family is declining sharply. Migration from urban areas due to marriages is also getting bigger and voluminous in coming decades this will in turn affect the cultural \& social structure of the society and a cosmopolitan culture will emerged.

Analysis of trend of the male \& females' migration it can be interpreted that share of employment \& education from other states to Jaipur is leading to stabilization \& it was not found significant for testing the hypothesis of equality of their share over decades. Whereas for people moving with family the share of males is getting stabilized though for females it was growing. If this scenario continue than growing migration of females in this category will, to some extent, be beneficial to the decreasing sex ratio the city.

Short distance migration which consist the in-migration from various parts of the Jaipur district to Jaipur Urban area is one a sharp decline path in terms of its contribution in total migration. It clearly indicates the tendency of migrating to Jaipur urban area is lower down as periphery of 
Jaipur urban area is also being developed as its suburb. Better connectivity is raising the number of daily commuter and in near future entire district may be developed as a part of Jaipur urban area and a new Jaipur is shaping up. In such a scenario overall migration to Jaipur urban area from the various parts of Jaipur district will lose its relevance.

\section{References:}

Bhagat, R. B. (992). Components of Urban Growth in India with Reference to Haryana: Findings from Recent Censuses, Centre for Training and Research in Municipal Administration, University of California, Nagarlok, Vol.24, No. 3, 1992, pp. 10-14

Bhattacharya, P. (1988). The informal sector and rural to-urban migration: Some Indian evidence, Economic and Political Weekly vol.33(21), 1255-1262

Jain, M.K., Ghosh, M. and Won Bae, K. (1993). Emerging Trends of Urbanization In India: An Analysis Of 1991 Census Results, Office of Registrar General, New Delhi

Registrar General of India: Census of India (1971, 1981, 1991, 2001) Migration tables Part V A and B, Rajasthan State. 


\title{
DISTRICT LEVEL ANALYSIS OF URBANIZATION FROM
}

\author{
RURAL-TO-URBAN MIGRATION IN THE RAJASTHAN STATE
}

\author{
Dr. Jayant Singh, Assistant Professor, Dept. of Statistics, \\ University of Rajasthan, Jaipur, \\ e-mail: jayantsingh47@rediffmail.com \\ Hansraj Yadav, Research Scholar, Dept. of Statistics, \\ University of Rajasthan, Jaipur, \\ e-mail: hansraj_yadav@rediff.com \\ Dr. Florentin Smarandache, Dept. of Mathematics, \\ University of New Mexico, USA, \\ e-mail: smarand@unm.edu
}

\begin{abstract}
Migration has various dimensions; urbanization due to migration is one of them. In Rajasthan State, District level analysis of urbanization due to migrants shows trend invariably for all the districts of the state though the contribution in urbanization by the migrants varies from district to district. In some districts the share of migrants moving to urban areas is very impressive though in others it is not that much high. The migrants' contribution in urbanization is on the rising over the decades. In this paper district level migration in the Rajasthan state is examined in relation to total urbanization and urbanization due to migration.
\end{abstract}

Broadly speaking rural to urban migration is due to diverse economic opportunities across space. Throughout history migration has played substantial role in the urbanization process of several countries and still continues to play similar role. In many cases it is witnessed that more the migration higher the urbanization rate. In general, it is perceived that migration has a fairly large share in urbanization and migrants constitute a significant portion in urbanization.

At all India level rural-urban migration seems to be modest as 2001 census discloses that net rural to urban migration in 1961-71 had been 18.7 percent, in 1971-81 it was 19.6 percent, in 1981-91 migration was 21.7 percent and in 1991-01 it was 21.0 percent. So the figures reveal that there 
has been continuous rise in the contribution of net migration to total urban growth since the sixties though between 1991 and 2001 there has been slight decline in the rate compared to previous decade.

Migration is defined on the basis on the last residence concept hence migration in the 2001 census refers to those who migrated in ten years (1991-2001) preceding the year of survey 2001. The gross decadal inflow of rural to urban migrants as a percentage of total urban population in 2001 turns out to be a little above 7 per cent at the all-India level (Table on next page). However, it varies considerably across states. Both industrialized states like Gujarat and Maharashtra and the backward states like Orissa and Madhya Pradesh show high rates of migration. Similarly examples can be found from both the types of states which have recorded sluggish migration rate, e.g. industrialized states such as Tamilnadu and West Bengal and backward states such as Uttar Pradesh, Bihar and Rajasthan. This reveals that share of the rural to urban migrants in urbanization differs from state to state. A table giving rural to urban migrants for the period 1991-2001 as a \% of urban population relation is given in table on ensuing page.

\section{Table 1}

\section{Rural-Urban migration for 1991-2001 as a \% of urban population}

States

Andhra Pradesh

Assam

Bihar

Gujarat

Haryana

Karnataka

Kerala

Madhya Pradesh

Maharashtra

Orissa

Punjab

Rajasthan

Tamil Nadu

Utter Pradesh
Rural-to-Urban Migrants (1991-2001) as a \% of Urban Population 
Source: Census of India 2001, Migration Tables.

Nevertheless, rural-urban migration rates at intrastate level have been a phenomenal in India as this flow dominates the interstate flows. Since the intrastate migration rates are much higher in magnitude than the interstate migration rates therefore it makes an interesting subject area to comprehend various economic, social and cultural factors connected closely with it. A district level analysis for Rajasthan state is thus attempted to perceive urbanization due to migration their interlinkages and affiliations.

\section{Urbanization Trend in the State of Rajasthan}

According to the census report of 2001 the share of urban population in Rajasthan has inched up to $23.38 \%$ as compared to $15.06 \%$ mentioned in the census report 1901. Number of towns in the Rajasthan increased to 216 in the census 2001 against 133 in the 1901 census that depicts $62.4 \%$ of growth in this period of time whereas at national level this growth has been $169.36 \%$ in same time span. Share of Rajasthan's urban population in the country dropped to $4.6 \%$ from $5.98 \%$ over a period of century whereas in terms of growth of number of towns, state share also slipped down to $4.18 \%$ from $6.94 \%$ in this same period of time. Therefore, it can be clearly claimed that Rajasthan has to go a long way to match with national figures as regards the characteristics of urbanization is concerned whether it is growth in urban population or towns. However, there has been a meager improvement in the percentage share of state's urban population in the national urban population as it has grown to $4.1 \%$ to $4.52 \%, 4.52 \%$ to $4.62 \%$ and then to $4.64 \%$ in last three successive censuses.

\section{District Level Analysis for Rajasthan}

The migrants contribution in urbanization is on the rising over the decades as $16.4 \%$ of the total migrants in the Rajasthan settled in urban areas during the period 1971-80 and the figure which went up to $22.4 \%$ 
during the duration 1981-1990 and further advanced to $25.4 \%$ in the duration 1991-2000. This trend is evident invariably in all the districts of the state though the contribution in urbanization by the migrants varies from district to district. In some districts the share of migrants moving to urban areas is very impressive though in others it is not that much high.

The census analysis of Barmer district of Rajasthan reveals that $7.7 \%, 7.1 \%$ \& $4.0 \%$ of total migrants moved to urban areas in last three decades i.e. 1991-2000, 1981-90 \& 1971-1980. This percentage share for Jalore was 9.6, 8.1 \& 4.7\%, and for Banswara it was 9.1, $7.9 \& 4.7 \%$. The figures disclose that these districts had poor share of migrants to urban areas. On the other hand there are districts like Jaipur, Ajmer, Kota and Bhilwara where the percentage share of migrants settling in urban areas with context to the total migrants is comparatively much higher. This percentage share of rural migrants in three last successive decades for these districts is given in table placed below.

Table 2

Share of Rural Migrants in selected Districts during last three decadal period

\begin{tabular}{|l|l|l|l|}
\hline District / period & $1991-2000$ & $1981-90$ & $1971-1980$ \\
\hline Kota & 56.8 & 54.3 & 50.7 \\
\hline Jaipur & 53.2 & 48.5 & 35 \\
\hline Ajmer & 41.4 & 35.6 & 28.7 \\
\hline Bhilwara & 31.1 & 25.0 & 14.8 \\
\hline Jodhpur & 26.8 & 18.7 & 12.4 \\
\hline
\end{tabular}

To apprehend the trends in the migration of population to the urban areas in different districts of Rajasthan, based on the share of urbanization due to migration can be categorized as follows:

Category 1: Higher During all the three decades

Category 2: Higher during 1991-2000 \& 1981-91 but lower in 1971-80

Category 3: Higher during 1991-2001 but lower in last two decades 
Category 4: Lower During all the three decades

Category 5: Lower during 1991-2000 \& 1981-90 but higher in 1971-80

Category 6: Lower during 1991-2000 but higher in 1981-90 \& 1971-80

Districts falling in Category 1 are those, which observed higher urbanization due to migration in comparison with state level figures during three consecutive decadal periods. In these Districts, the proportion of migrants coming to urban areas is higher than the state proportion of such migration.

District falling in Category 2 performed better as far urbanization due to migration in last two decades is concerned. Districts in this category observed higher urbanization share due to migration than what was seen in the state in last two decadal times whereas three decades back share of migrants to urban areas was lower in these districts from that of state in overall.

Similarly, Category 3 is featuring districts that have observed higher urbanization share due to migration than to state in recent decade though that particular district was falling below than state share in two previous consecutive decades.

Category 4 to 6 are counterpart of category 1 to 3 where share of migrants moving to urban areas in total migrants for a district is lower than state share of migrants moving to urban areas as regards total migrants of the state.

Table 3

Classification of District according to Urbanization Trends in last three decades

\begin{tabular}{|l|l|}
\hline Category & Districts \\
\hline Category 1 & $\begin{array}{l}\text { Ganganagar, Bharatpur, Swaimadhopur, Jaipur, Pali, } \\
\text { Ajmer, Kota }\end{array}$ \\
\hline
\end{tabular}




\begin{tabular}{|l|l|}
\hline Category 2 & Bhilwara \\
\hline Category 3 & Jodhpur \\
\hline Category 4 & $\begin{array}{l}\text { Alwar, Dholpur, Karauli, Dausa, Sikar, Nagaur, Barmer, } \\
\text { Jalore, Sirohi, Tonk, Bundi, Rajsamand, Udaipur, } \\
\text { Dungarpur, Banswara, Baran, Chittorgarh, Jhalawar }\end{array}$ \\
\hline Category 5 & Bikaner, Jhunjhunu \\
\hline Category 6 & Hanumangarh,Churu \\
\hline
\end{tabular}

Classification elucidated above undoubtedly depicts that there are only seven districts where there is larger urbanization due to rural migrants in context with the overall state level migration and urbanization figures over three consecutive decades. Notwithstanding there are 18 districts having lower urbanization due to migration than to state level migrant urbanization.

2001 census report explains that Jodhpur is the only district where urbanization due to migration has improved with regard to the figure of state in total. Similarly, district Bhilwara has witnessed this edge in two recent decades. In two recent decades there is improvement in the data of Bhilwara in relation to urbanization due to migration is concerned decades otherwise three decades back the urbanization due to migration for Bhilwara was lower than state figures. Jodhpur showed this improvement in last decade even though it was lagging behind in two previous decades.

Bikaner and Jhunjunu are way behind in showing any improvement in urban migration to state share in last two decades while Hanumagarh \& Churu showed no improvement only in last decade. Jaiselmer is the district that doesn't observe any clear-cut pattern on account of migrants share in relation to state.

\section{Urbanization and Migration:}


It is well evident that number of rural migrants as regards total migrants is considered as an extent of urbanization by migration in a particular category. Districts are classified in the groups where percentage of migrants attributing to urbanization is $<20 \%, 20-50$ and $>50 \%$ in all the three durations 1971-80, 1981-90 and 1991-2000 and the result is summarized as below:

Table 4

Number of Districts according to range of Urbanization in last three Census

\begin{tabular}{|l|l|l|l|l|}
\hline \multirow{2}{*}{ Range of urbanization (in\%) } & 2001 & 1991 & 1981 \\
\cline { 2 - 4 } & \multicolumn{3}{|c|}{ Number of Districts } \\
\hline$<20$ & 10 & 16 & 28 \\
\hline $20-50$ & 20 & 14 & 3 \\
\hline$>50$ & 2 & 2 & 1 \\
\hline
\end{tabular}

Its is evident from above classification that there is stark variation in the urbanization by migrants in various census barring the category of the districts that are having $>50 \%$ of urban migrants in total migrants as there are only district since last two census against one three decade back where as considerably shift in the other two categories of $20-50 \%$ and $<20 \%$ urbanization due to migration is there in this three decadal period. There are more districts classified in the category $20-50 \%$ during the recent decades whereas the number of districts in the category $<20 \%$ has gone down in the recent decades.

Comparative Analysis of Total Urbanization \& Urbanization due to Migration: 
Migration is an important part of the urbanization and in many cases it is attributing predominately in the urbanization. Indicator of rate of Urbanization can be defined as below:

1. Total Urbanization rate: is the percentage of population living in urban areas to the total population

2. Urbanization rate due to migration: is the percentage share of rural migrants to the total migrants.

The result of the comparative investigation made on the basis of above mentioned two indicators for the last decadal period i.e. 1991-2001 is examined in coming paragraphs.

State urbanization rate is the share of urban population to the total population at state level and similarly it is counted on districts level. Consequently these two rates are compared at state and districts level to analyze the urbanization trend and to establish its association with the migration. At state level $23.4 \%$ of the total population is urbanized and $22.9 \%$ of migrants are coming to urban areas thus at state level the urbanization rate through migrants is compatible to the total urbanization rate. Barmer and Jalore are two districts in which urbanization through migrants' rate is below $20 \%$ as the urbanization rate of the migrants to these districts is mere $15 \& 19 \%$.

Rate of urbanization through migrants in Jaipur is (73.6\%), Kota $(68.2 \%)$, Ajmer (53.8\%) and Udaipur (50\%) and thus these districts have more than $50 \%$ of rural migrants and this can be summed up as more than half of the migrants to these districts are settling in urban areas. Bikaner and Churu are the only districts observed where urbanization through migrants rate is lower than total urbanization rate of the state. This difference was more than $32 \%$ for the Udaipur and Banswara districts and for seven districts it was more than $20 \%$. The classification of number of districts based on the range of these two urbanization indicators is classified in coming table.

Table 5

Total Urbanization Rate vis-à-vis Urbanization Rate due to Migration 


\begin{tabular}{|c|c|c|c|c|c|c|}
\hline $\begin{array}{l}\text { Range of } \\
\text { Urbanization }\end{array}$ & & $>50 \%$ & $\begin{array}{l}40- \\
50 \%\end{array}$ & $\begin{array}{l}30- \\
40 \%\end{array}$ & $\begin{array}{l}20- \\
30 \%\end{array}$ & $<20 \%$ \\
\hline $\begin{array}{l}\text { Combined (Male } \\
\& \text { female) }\end{array}$ & $\begin{array}{l}\text { Total } \\
\text { Urbanization }\end{array}$ & 1 & 2 & 2 & 8 & 19 \\
\hline Male & & 1 & 1 & 2 & 9 & 19 \\
\hline Female & & 1 & 1 & 3 & 7 & 20 \\
\hline $\begin{array}{l}\text { Combined (Male } \\
\& \text { female) }\end{array}$ & $\begin{array}{l}\text { Urbanization } \\
\text { rate due to }\end{array}$ & 4 & 5 & 8 & 13 & 2 \\
\hline Male & migration & 12 & 8 & 4 & 9 & 12 \\
\hline Female & & 2 & 2 & 11 & 10 & 7 \\
\hline
\end{tabular}

Clearly the migration witnesses a better urbanization rate and there are more districts classified in higher range of urbanization rates than the number of district classified in lower range in accordance with the total urbanization rate of the districts.

Technique of non-parametric test is used for district level analysis of the urbanization to examine the migration to different districts having same size of population. District are ranked on the basis of the total urban population and urban population due to migration and these formed two groups of Non-parametric test and Wilcoxon - Mann/Whitney Non parametric Test is employed for equality of $\mathrm{K}$ universes for total population and Male \& Female population and results of the analysis done in Megastat is as below:

\begin{tabular}{|l|l|l|}
\hline \multicolumn{2}{|l|}{ TOTAL } & \multicolumn{2}{l|}{} \\
\hline $\mathrm{n}$ & sum of ranks & \\
\hline 32.00 & 698.00 & Group 1 \\
\hline 32.00 & 1382.00 & Group 2 \\
\hline 64.00 & 2080.00 & Total \\
\hline & 1040.00 & expected value \\
\hline & 74.48 & standard deviation \\
\hline & -4.59 & Z \\
\hline
\end{tabular}




\begin{tabular}{|c|c|c|}
\hline & 0.00 & p-value (two-tailed) \\
\hline \multicolumn{3}{|l|}{ MALE } \\
\hline $\mathrm{n}$ & sum of ranks & \\
\hline 32.00 & 612.00 & Group 1 \\
\hline 32.00 & 1468.00 & Group 2 \\
\hline \multirow[t]{5}{*}{64.00} & 2080.00 & Total \\
\hline & 1040.00 & expected value \\
\hline & 74.48 & standard deviation \\
\hline & -5.74 & $\mathrm{Z}$ \\
\hline & 0.00 & p-value (two-tailed) \\
\hline \multicolumn{3}{|c|}{ FEMALE } \\
\hline $\mathrm{n}$ & sum of ranks & \\
\hline 32.00 & 775.00 & Group 1 \\
\hline 32.00 & 1305.00 & Group 2 \\
\hline \multirow{5}{*}{64.00} & 2080.00 & Total \\
\hline & 1040.00 & expected value \\
\hline & 74.48 & standard deviation \\
\hline & -3.55 & $\mathrm{Z}$ \\
\hline & .0004 & $\mathrm{p}$-value (two-tailed) \\
\hline
\end{tabular}

Clearly, the above examined district level analysis reveals that total urbanization and urbanization due to migration differs significantly. Male and female population and districts have significant impact on total urbanization \& urbanization due to migration. Thus the relative magnitude of total urbanization and urbanization due to migration differs significantly for the districts for both genders and combined.

\section{References}

1 Amitabh Kundu, "Urbanization and Urban Governance: Search for a Perspective Beyond Neo-liberalism", in A. Shaw ed. Indian Cities in Transition. Orient Longman, Hyderabad, 2006.

2 Gurinder Kaur, Migration Geography, Anmol Publications, New Delhi, 1996.

3 J G Williamson, "Migration and Urbanization", in H Chenery and T N Srinivasan eds. Handbook of Development Economics. Vol. 1, Elsevier Science Publishers, North Holland, 1988. 
4 Prabir C. Bhattacharya, "Rural to Urban Migration in LCDs: A Test of Two Rival Models". Journal of International Development. Vol.14, No.7, 2002.

5 Ravinder Kaur, Migrating for Work: Rewriting Gender Relations", in Sadhana Arya and Anupama Roy eds. Poverty, Gender and Migration. Sage Publications, Delhi, 2006.

6 S K Sinha, Internal Migration in India 1961-81. Office of the Registrar General. Ministry of Home Affairs, New Delhi, 1986.

7 Somik V. Lall, Harris Selod and Zamarak Shalizi, "Rural Urban Migration in Developing Countries: A survey of Theoretical Predictions and Emperical Findings." Development Research Group, World Bank, 2006. 


\section{The emerging clan capitalism in the world*}

In the present article a number of critical economics situations are discussed based on clan capitalism as starting point. One can see clearly then, that instead of assuming 'ordinary economy' and clan/crony capitalism is an exception in particular nation because of certain socio-historical context, one should begin with the opposite assumption instead: that clan capitalism can be found almost everywhere in this planet.

\section{Introduction}

Many economists think that economy of any particular nation is something more or less like building a house: in that sense if all people work to maximize their utility (cf. Adam Smith) then eventually the house will be built properly, especially if market mechanism is allowed to function properly without too much government intervention. But nowhere in this world, this simple perceived assumption works. Mostly, either excessive market liberalization advocated by laissez-faire and neo-liberalism proponents gives worst result (crises) or government intervention is too heavy, and then there is no incentive for enterprises to innovate and create new products and services.

Based on a number of previous study, (cf. Yoshihara Kunio and Mancur Olson), then we submit another approach, that is: instead of assuming 'ordinary economy' and clan/crony capitalism is an exception in particular nation because of certain socio-historical context, one should begin with the opposite assumption instead: that clan capitalism can be found almost everywhere in this planet (not only in Russia, latin America, or Japan), and if in a few nations there are normal/ordinary economy where all group of functions work well, that is only an exception. West Europe apparently perform quite good compared to other regions in the world in this respect, but one should be aware because as globalization takes full effect in the coming years, then just like a virus can spread all over the world, similarly clan capitalism can be transported and transformed on board to other countries. Excessive financial liberalization and integration can introduce further vehicle which can be used by those clan groups to take advantages.

\footnotetext{
*written by V. Christianto, email: VictorChristianto@gmail.com
} 
Kunio [12] have conducted studies on south east asia, while Mancur Olson[18] based his study on Russia economy in 80-90s. But then we know that similar situation can be extended to either USA or Japan economy,[1][6] i.e. that clan capitalism or ersatz capitalism can be found in all national economies both in developing countries and developed countries alike. The old phrase that 'money is the root of all evil' can be extended to become 'the root of all evil is money, power and clan.' To put emphasis on this framework, we should say that there is no such thing as a perfect building or house, because each house imposes particular defect or imperfection, just like in Le Corbusier's imperfection architectural style in the past decades.[17] The question then is to start with such defects as norm, and then work based on that situation.

We hope that this article can be considered as starting point for imperfect economy study (not only asymmetric information), based on starting hypothesis that there is no such thing as 'normal economy.' All economy is influenced by a number of clan groups and also numerous sub-groups which join to those clans' back wagon, and those create an ersatzcapitalism infected economy.

Quoted from a recent article: "This echoes some other crony capitalism contexts - Russia comes to mind - but differs from others, such as many cases in Latin America, and is unusual in a country with as much recent political stability as America."[1] That is what is supposed to happen in US.

\section{What does happen in russia?}

There are a number of viewpoint arguments have been pointed out to explain problems in Russia economy, i.e. neoliberalism, (neo-)keynesian, and clan capitalism argument. Of course, the neoliberalism proponents would argue that liberalism advises have never been put into practice, as quoted from an article: "In short, the neo-liberals explain the collapse of the Russian economy in terms of the perverse incentives provided by the policies and practices of the Russian government: failure, corruption and criminality is rewarded, while legitimate business activity is penalized. The collapse of production and investment is the result of the absence of the 'order and good government' that is the necessary foundation of liberal capitalism."[2] And the keynesian proponent will argue that excessive liberalization and privatization has been put into effect in the past decade without sufficient preparation and transition, which then make the situation even worse.

The third argument, that is by clan capitalism proponent, would say that clan groups always take place amidst the transition process and their activities include sabotaging numerous amount of development fund from external sources for their own clan groups. At the end of the transition process, then the economy takes the form of strengthened and 
consolidated clan capitalism, where excessive power is obtained by a few number of clan groups only, while leaving the rest of the public remain in suffering condition. A short description is given as follows:

"Under crony capitalism selected economic elites receive preferential treatment and privileges, thus making support from the state rather than market forces a crucial factor for maintaining and accruing wealth."[3]

Then one need to define what is clan capitalism. A useful term is suggested by Kosals[4], that is clan capitalism, which possibility to become worsening further and become oligarch capitalism [4, p.8]. The purpose of clan is as described as follows:

\footnotetext{
"First of all, such clan isn't a group of relatives but it is business entity with for profit activity...The general strategic purpose of the clan is to accumulate the resources and to expand its power and influence in the field of operation. Every clan intends to reach a stable position and to control external environment, to create favor external socioeconomic and political conditions. Many clans desire to become a monopoly to protect internal operation." [4, p.11]
}

According to Kosals, elements of the clan include [4]:

a. chieftain: that is charismatic leader which control all operations of the clan;

b. the core: key persons which are closest collaborators of the chieftain.

c. skilled professionals: that is specialists who are hired with high salary.

d. ordinary members: those are specialists and manual workers employed in business entities.

e. agents of influence: people outside it but serving it because of their unique positions in the media, law enforcement agencies etc.

Quoted from Kosals: "the most powerful clans are in industries dealing with extraction, processing and export of natural resources (oil, gas, metals); FSB; financing; military; law enforcement agencies; defense industries." [4, p.20] Other quote: "The biggest clans at every level headed by so called oligarchs. There are around one - two hundreds of oligarchs at every level, therefore, obviously, near one thousand oligarchs are operating in Russia totally" [4, 23]

The situation apparently do not happen only in Russia, but also in Latin America. Quoted from Kosals: "Cronyism is one of the specific features of clan capitalism. It was examined in detail within analysis of the specific model of capitalism developing in Latin America crony capitalism." [4, 27] 
That is why, one need to take a look further on the impact of clan capitalism and its respective negative impact to overall economy of a given country. One should begin that clan capitalism which is inevitably infectious but already epidemic in numerous states, either in the form of shadow economy, crony capitalism, ersatz capitalism, clan capitalism, or even oligarch economy. One can even hypothesize that actually clan capitalism is more than exception as often assumed; it is market economy governed by small business entities which is an exception. There is no such thing as free market economy, as all economies are cronies-infected.

Clan capitalism is a chronic disease, but the fact is that all economies suffer from more or less the same chronic disease. See Appendix I for responses to a questionnaire.

\section{Japan economy, boryokudan, and botaiho}

While it has been neglected in standard economics textbooks, clandestine groups such as yakuza can affect up to $40 \%$ of Japan economy problems. Quote: "The emergence of Jusen companies, which had strong links with Japanese mafia, otherwise known as Yakuza, proved to be one of the major hurdles in the Japanese banking reforms. The Jusen problem exposed the nexus between banks, Ministry of Finance and yakuza. ...Later, it was also revealed that some officials in the Ministry of Finance had strong links with yakuza." [5, p.3]

While one can think otherwise that such a yakuza(boryokudan)-related issues are diminishing, it has been concluded that: "The yakuza plays an important role in the Japanese financial system even today, thanks to the involvement of banks in the real-estate sector during the bubble period. These problems continued to haunt the Japanese banking sector and some believe that it was more of a socio-cultural problem than purely an economic one..." [5, p.5]

Unlike in Russia Federation, where clans are mostly organized around their chieftains, yakuza organizations are apparently more stable, with three big syndicates, i.e. yamaguchigumi, inagawa-kai, and sumiyoshi-kai [6, p.1]. Quite related to the problems emerge which are caused by such clandestine organizations including yakuza, there are concerns raised recently pertaining to possibility of Japan economy to experience similar crisis compared to what happen in Greece in the beginning and the first quarter of 2010. However, there is significant difference here, that is that Greece economy problem is not yakuza or clan related, while one great obstacle to reform Japan industrial sectors and also financial sectors alike were their relationship with yakuza and other clandestine groups, which have been tolerated since Showa era.[6] 
Then with regards to question whether one should do or not do economics reformation, one can also refer to another recent suggestion by Posen (2009) that "but if you take a broader historical perspective, that essentially hesitation to finally fix the banks is what kept Japan from doing the right thing, in a sense, throughout the 1990s."

\section{Lesson to learn: how to take proper measure on clan capitalism}

And with regards to spectrum of choices available to policy makers, one first shall bear in mind that the clan capitalism are already there for quite some time, and that includes possibly a number of politician, and senate member, and other party alike, including a number of high-profile elites known as 'oligarch', which mean that it would take more than one sweep to clean up all the mess. Therefore, apparently there are only a limited number of possible approaches in order to take proper measure on those clan capitalists, such as:

a. anti-clan regulation: in Japan there was passage of anti-yakuza regulation which restrict their actions (botaiho), while at the same time give time for them to 'evolve' to put their feet on other kind of transactions.[6] In other countries too, such an anti-clan regulation can be put into effect, not only anti-drugdealing or anti-humantrafficking. In the case of Japan, the situation after passage of botaiho indicate decreasing attractiveness of joining clan group: "young males are ceasing to find gang membership an attractive career choice." [6,p.11]

b. very strict measures: just as what China do to all alleged problematic politicians or governors. But if too many clan-related politicians are involved in law enforcement agencies, and then perhaps this method may not be practically viable. See Figure 1 for illustration.

c. clean up the government offices first: this can be effective if one can estimate how many number of politician in government body and also in regional offices which are involved or participate in the predominating clans, then removing all of those clan-related officers can be a good choice. However, such a policy may not be viable in other countries, perhaps Russia, where state-clan relationship are quite neat and where it is not so easy to imagine that government officers can function without those chieftains entity. Military involvement in a number of clan-groups can make matters more difficult. 
d. breaking the chains: one possible countermeasure of the clan's improper involvement in policy making is to identify the clandestine people which are not exactly part of the clans, but they play the role of intermediaries among clandestine groups and government officials. For instance, if one think that there are a few huge clans which can affect US national economy and those are oil-industrial-military complex clans, then perhaps one should track down to $\mathrm{d}$. rockefeller and zbigniew brzezinski if one wish to break their chains. For other example of oil-military industry clan group, see Carlyle group as discussed in Goodman \& Goodman[11]. One can think that it is not unlikely that those clan groups can affect also news media and academic institutions (see diagram 2).

e. network analysis: one of recent tool to analyze gang's network is using network analysis. This method has been advanced by a number of theoretician, but in principle the same method can be used to find out how a clan is related to media, government officer, scientist, economist, public media, and perhaps policy influencer. Stop to think that economists including neoliberalist proponents are only doing their job as scientist. Of course, some economists are doing their job well for the wellness of a nation, but others are only profit maximizer, hence one good solution is to minimize their role as good policy-maker as a counter-measure to the clan groups' influence to their advantage.

f. autopoeisis [8] and bacteria analogy: Autopoiesis can be defined broadly as ability and mechanism of bacteria and other life cell to retain its life: "The main feature of autopoiesis is the self-maintenance due to a process of self-generation from within. Although this concept came from the analysis of a living cell, it can be metaphorically applied to social systems."[8, p.9] One can think that bacteria rely on and make interaction with their environment in order to get what they need and to give supporting conditioning. Similarly, a mafia or clan groups take much from their environment and people surrounding them in order they can continue their excessive spending. For example, it has been estimated that Japan economy suffer from yakuza clan groups because some $40 \%$ of transaction or project involve them. If then we assume a moderate estimate of $3 \%$ to $5 \%$ of 'security protection' then the amount siphoned for their clans amount to $40 \%$ x $3 \%=1.2 \%$. Similarly, in Russia economy, especially in metallurgy and oil producing and other natural resources industries, there are significant role played by clans and oligarchs, which at a time can influence russia economy and private business up to $70-80 \%$ around 90s.[10] Some of them ask that fee with label such as security protection, but you know that sometimes such extra security fee takes place because there are competition among clans themselves (that is, a client should hire a clan for protection against violence threat exercised by another clan). Therefore, in order to suppress and reduce actions of those clan groups, one need to 
understand better how the autopoiesis mechanism are used by bacteria to survive and grow in their environment, and then how to minimize their activities. One possible approach is to introduce obstacle in order those bacteria and virus will not escalate and move beyond their present environment. And after that, reduce and minimize their effect within that obstacle/barrier.

Other problem is that a number of those clan groups are already moving abroad, that is they become so large group and then they decide to go global. Such a globalization of clan groups can be thought of as parallel with virus which becomes epidemic.[8] There is no such easy measure to counter this tendency, for instance considering the increasing transactions related to human trafficking, drug dealing etc., which sometimes those large clan groups got support from other clandestine groups, that is secret agencies. Some of those secret agencies may need large support to continue their programs abroad, and they think that drug dealing etc. can be their vehicle for finding those support.[11]

g. counter-incentive measures: another difficult part for breaking the chains among the state and clan groups is to provide a proper scheme for young people in order they can stay away from clan groups. For instance, during a conversation with a Russia young man sometime ago, this writer were told that it is often a compulsory for an average high-school graduate young boy whose parents are not rich to be military officer, at least to serve there for a number of years, while other high-school graduate young boy who has rich parents is not required to be military officer. Then after a while, that average young boy would find himself to get lack of option to get normal wealthy. Perhaps this reasoning can explain why for some young boys/girls the only choice is to support or join a clan group in one or other way (for example, to become drug dealer), especially if he/she got lack training in other skills. That is why: being a part of clan groups (be it yakuza, or drug dealer, or other clandestine groups in asia) is an 'incentive' for those average young people because that path offers a short-cut to become wealthy in short time. One can perhaps reason that a proper counter-incentive scheme to reduce such a tendency to join clan group, is by offering support, perhaps by some kind of business start-up support to at least $10-20 \%$ of the brightest of those average young high-school graduates in order they can begin their own start-ups. Therefore, giving good incentives to new start-ups by young people is not only good practice for economics reason (creating new entrepreneurs), but perhaps it is also a good counter-measure toward joining clan groups which can devastate a nation's economy in the long-run.

Along with an effective anti-clan regulation such as botaiho in Japan, then implementing such a counter-incentive can be an effective approach. 


\section{Different paths towards healthier economy}

The following figure (Figure 1) is a simplified diagram on how each nation can follow different paths towards the idealized model that is economy composed of business enterprises which are less oligopolized and all of them work to be more effective and efficient while creating better and useful products and services to the market. There can be six possibilities, i.e. ranging from equal enterprises, clan capitalism, and oligarch capitalism (the worst situation), in a condition of either laissez-faire or state intervention. What characterizes region 6 is that there should be more or less equal playing field for all equal enterprises, which prevent them to form oligarch formation which can make the entire economy less competitive. Of course such an idealized condition is difficult to achieve, because each large enterprise always have tendency to form oligopolistic situation.

For example, the path experienced by Russia is not from centralized state-owned oligarch corporate (for instance in metallurgy industry) toward many private enterprises in a liberalized and laissez-faire environment (region 6), but instead from region 1 to region 4 . That is a path to clan capitalism. And if the situation is worsening, then it can move toward region 2 (oligarch capitalism).

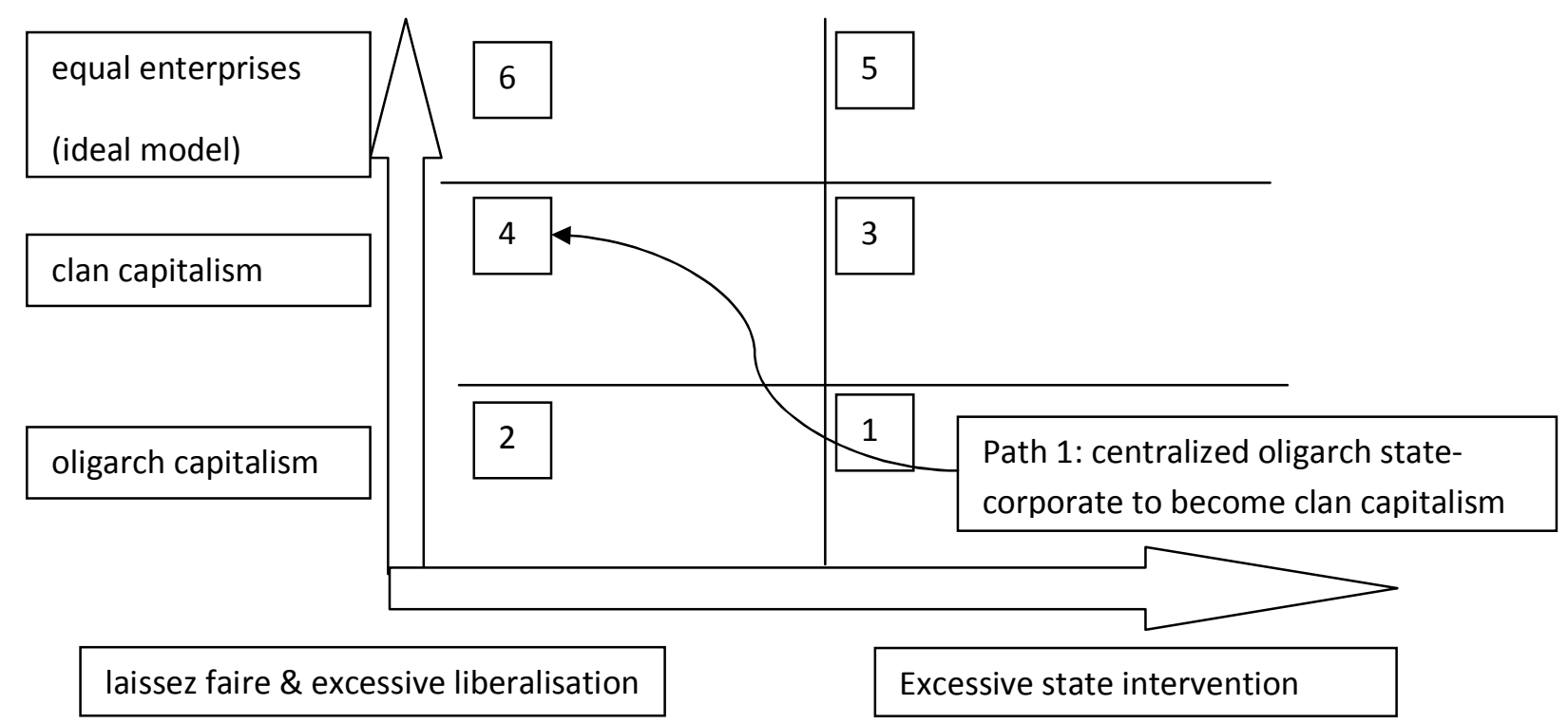

Figure 1. six possibilities of a nation's economy path toward healthy economy

Therefore, without strict, realistic and drastic measures to handle those clan groups, then they can turn the entire economy to become oligarch economy, which is unlikely to bring a better and healthier economy for most people in the federation. 
The situation of Japan economy is a bit more advanced, because there are no apparent clan groups, except those boryokudan clans and also a few major enterprises who form interrelated groups called a cartel and predominate the industries.[5] Quote:" They also acted as cartels that led to monopolization of the Japanese industries."[5]. It is not quite clear what is the present path of progress, whether that is to reach region 2, or to region 4 , where a few number of clan groups predominating the whole economy. Nonetheless, Japan economy seems a bit in better situation compared to Russia because they did not experience long time period under state planning and state-owned corporate who control all production and supplies.

Another thing worth to consider is to study the pattern of 'clotting' of those clan groups among other democracy and economy institutions. In this regards, one can remember Amartya Sen's hypothesis sometime ago that is: that democracy can affect distribution of wealth in a given nation, and that bad democracy may bring unequal distribution of products, which make many people in a nation suffer much more. If we extend this hypothesis a bit further, then one can hypothesize that (i) there is always tendency for clan groups to influence democracy system including news/media as the fourth pillar of democracy, in order to alter the course of distribution of resources for their advantage. To put this effect, see the diagram 2 below.

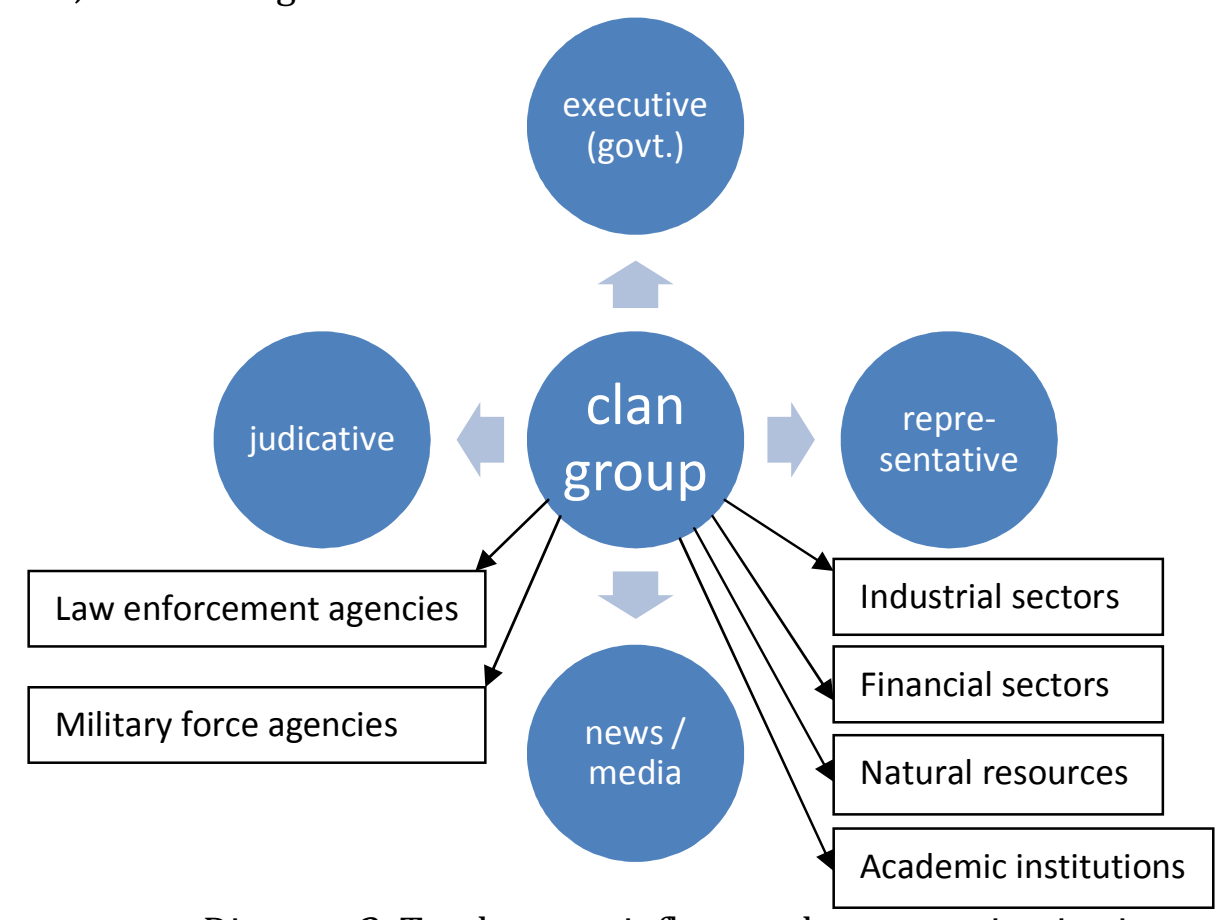

Diagram 2. Tendency to influence democracy institutions

That is why we learn that it is quite common in Russia that a major clan group to own not only manufacture or metallurgy corporate, they also own mass media channel in order to serve their own needs. 
In summary, not only those clan groups want to control industrial sectors, financial sectors, and natural resources for preservation of their interests, they also want to influence democracy institutions including law enforcement agencies for their advantage. That is typical acute problem in Russia and perhaps in other countries including latin America, and that is exactly what makes the ordinary public suffer more. One can distinguish how such 'clotting' developed among clan and democracy institutions by using analogies of malevolent virus or bacteria take over human body:

a. Stadium 1: they will accumulate influence in mass media /news corporate. An antioligopoly of mass media ownership such that no big clan can own more than $40 \%$ of total mass media can be put in effect. In USA similar regulation apparently has been put into effect to avoid such massive media ownership. See a bracket in diagram 3.

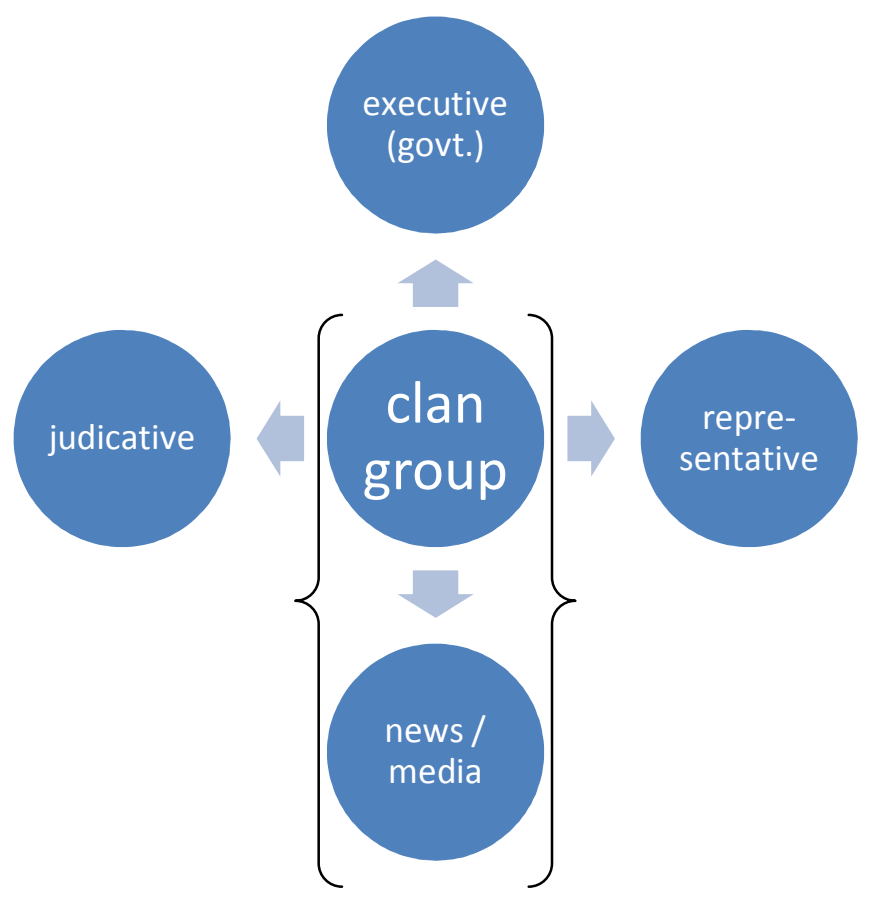

Diagram 3. Tendency to influence news / media

b. Stadium 2: they will accumulate influence in executive institutions, to become associate or senior staffs of the ruling government (clans). Such a practice apparently have become quite common in russia. See another bracket in diagram 4 . 


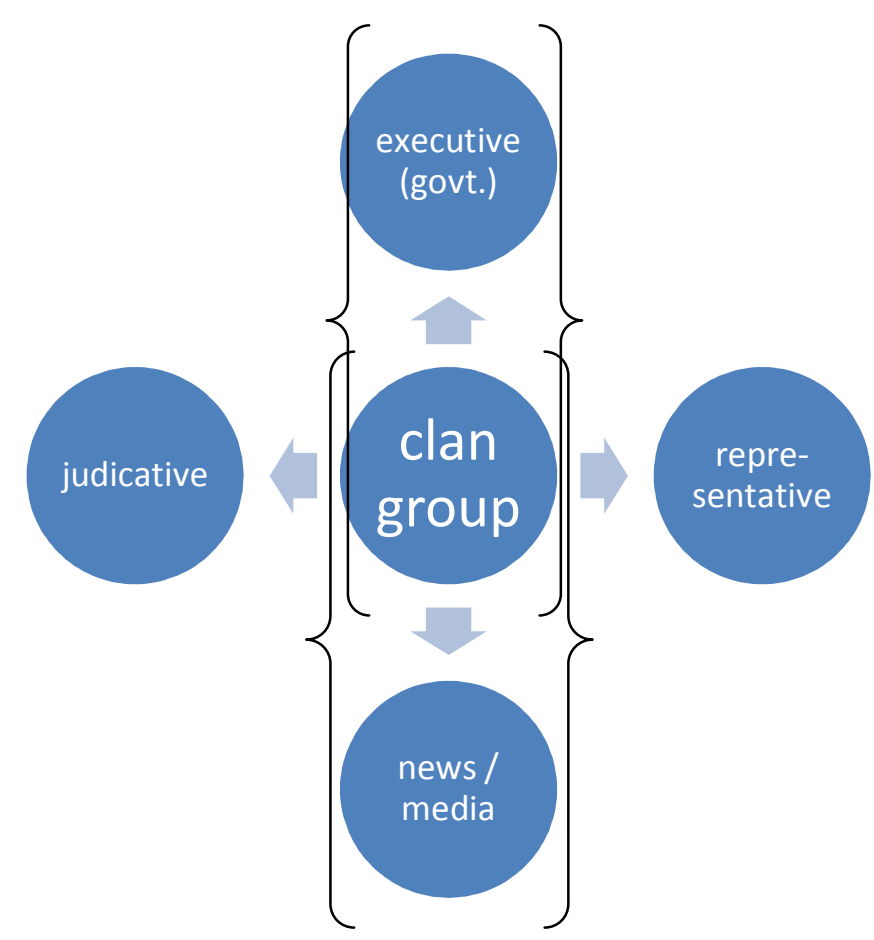

Diagram 4. Tendency to influence news and also executive (government officers)

c. Stadium 3: they will accumulate influence among house of representative (senate), including but not limited to buying vote in order to put a number of their member in house of representative. Similar to diagram 4, but there is also bracket from clan groups to house of representative.

d. Stadium 4: they will accumulate influence among judicative institutions, including if possible in law enforcement agencies. They will do their best attempt to block each new regulation which are intended to limit their clandestine activities. Pattern toward this attitude can be found in almost all clan groups including in developed countries. Similar to diagram4, but there is also bracket from clan groups to house of representative, and also from clan group to judicative institutions.

e. Stadium 5: is perhaps the worst possible scenario, where a number of predominating clan groups already take over the entire democracy institutions including executive, house of representative, judicative institutions, and also they manage to control majority of mass media. Not only that, they also extend their influence to military force agencies, which mean that they are practically control a nation. ( see diagram 2) If this situation take place, then it would be very difficult to reverse democracy institutions to become function normally again, because each effort to return back normal democracy can be blocked by those clan members in other institutions. Therefore government and other democracy institutions in 
particular nation should work hard in order that the clan group viruswill not take over all institutions and reach stadium 5.

Of course, the above diagram is merely a simplified sketch, and the real situation can be much more complicated, for example a number of clan groups can manage to control a number of education institutions which make them favorable in the opinion of academicians, and that perception can be proved to be beneficial them in the long-run because some of those academicians can be persuaded to follow their actions. For instance, if those academicians are participants of adviser group in a country, then they can make false suggestion and advice because of particular interests. That is example: shleifer as adviser to Russia transition. [15]

Note: the above analogy of clan actions and 'stadium' of cancer in human, is not a new analogy. There is a review of book with title The cancer stage of capitalism. Quoted: "the host body's immune system does not respond to the cancer's advance, because the communication systems of host social bodies across the world are themselves subordinate to transnational capital and largely reject and refuse to disseminate messages that identify the source of the disease." [16] That kind of neglecting that clan groups is part of the problem, not solution, can be found among students and other academicians, because they do not realize where the problem begin, and to some of them those clan groups are really powerful and look amazing, so they tend to submit to their power.

\section{There are variations of clan group interaction with external sources}

Diagram 2 above indicate possible interaction made by a number of clan groups to extend their influence to democracy institutions in their country. But there are situations where such a clan group can also influence other country's democracy process (such as Carlyle group[11]), and some clan groups can also take advantage of external sources, such as development fund (that is what happened in Russia, and perhaps a number of Africa countries).

Ordinary people may think that oil-industries have nothing to do with them, but they forget that sometime those large oil-industries can make effect such that the state supports their actions in foreign countries, and that can mean a long-period of economic stagnation because the state and public as a whole effectively should take the burden to finance those oil-industries' foreign adventures. [11]

Other example, during privatization process in Russia under Anatoly Chubais, A. Shleifer can be thought of as playing clandestine role while allowing a huge amount of sum went to Russia under the flag of privatization program, which in reality the sum were siphoned off 
the Russia economy [9]. The net result is that the Russia economy is not getting better, even if we compare with other formerly-socialist nations.

One can think that actually there were not privatization at all, but only a huge sum of foreign money which were used to boost power equity of such clans. Therefore A. Shleifer et al. who have also written their version of transition in their book 'Without a map' can be considered of such a chain or intermediaries of those clandestine clans in Russia. See for instance Lyndon LaRouche's report [7]. Shleifer's wife Nancy Zimmerman is a close associate of present minister of treasury of U.S, that is larry summers.[9]

Furthermore, there have been allegation that shleifer and his colleagues who have to assist Russia in their transition, has purchase a number of stake in oil corporation, which can make his decisions to be influenced by a number of special interests. Quoted: "Shleifer and Hay, who ran Harvard's Russia project, secretly bought large personal stakes in Russian oil companies."[15]

The effect of clan groups to development fund can be tremendous, because they will make sure to get beneficial effects from development fund and other external sources. And they will use all government (executive officers) in their disposal to make a way to accomplish their purposes. And if there is 'trickle-down' effect, then such development fund will be trickling down only to those clan groups. Such a problem can be found not only in Russia, but also in other developing countries, where a number of reports say that development fund only make a dictator in developing country to be more powerful.

This situation can be illustrated by diagram no.5, where there are double triangle, where a clan group will try to influence and gain control, i.e. military forces agencies, oil (natural resources), development fund, and advisers. Now you see that even economic advisers and development fund from external sources can be influenced and altered during the process in order the net effect is always beneficial for those ruling clan groups.

We do not mention here other black market activities such as illegal import and export activities, which may or may not be related to clan group activities. Of course, if those activities in particular illegal importing or exporting of things related to drugs, then these activities are more likely related to clan groups. Limiting and decreasing plantation area of those plants which form as natural source of those illegal drugs can be effective (let say to decrease plantation area by $1-10 \mathrm{~km}^{2}$ per year), in this regards, but of course that would not be an easy task for law enforcement agencies in particular country, in particular because there are external market which include their own clans who are interested in those plants, and they already form connection with legal or illegal military forces (see diagram 5). That is why, one necessary step is to detach tentacles of those clans in government and military offices. 


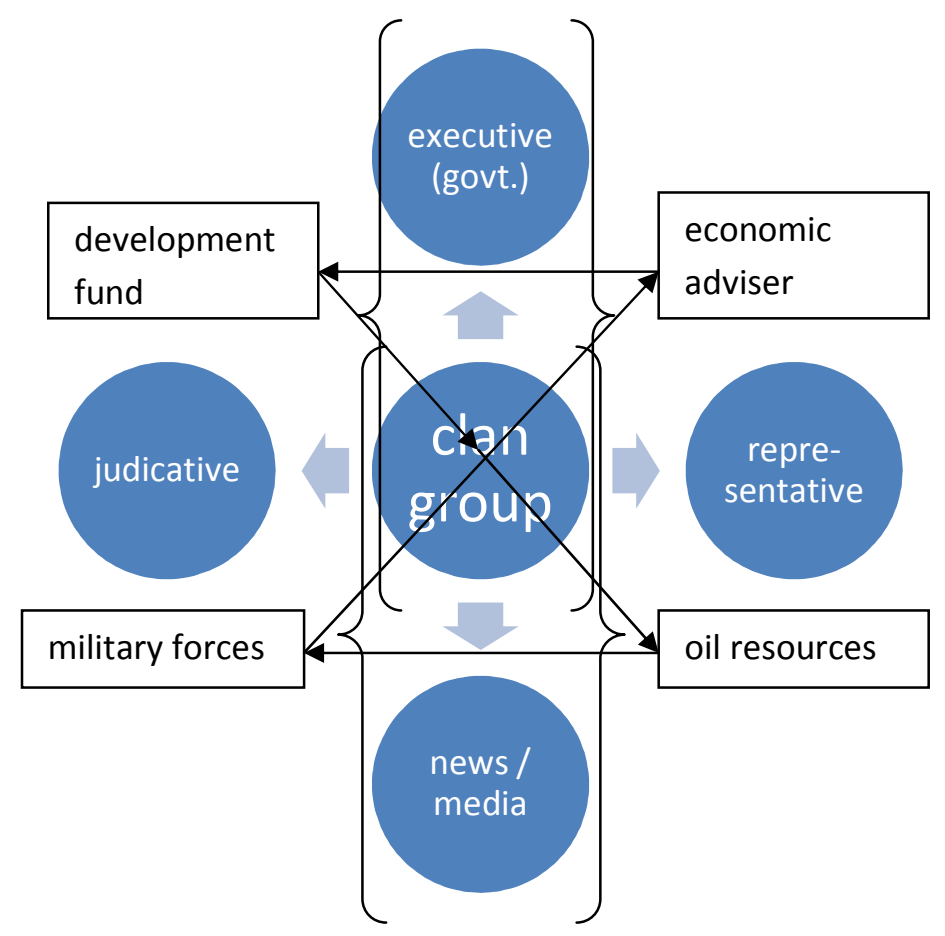

Diagram 5. Tendency to influence military, oil, adviser, and development fund

\section{Is there advantage for excessive liberalization?}

Unlike the common view based on neo-liberalism ideology, one should realize that going to excessive liberalization (region 6) is very unlikely to bring a healthier economy, especially when there are influential clan and oligarch groups, because they are likely to form better situation for their own advantage, and that is why there is strong tendency to prevent other private enterprises to grow and to be mature. At the end the result will be more or less like oligopoly situation in almost all industries, which real effect is likely to turn the entire economy to be less competitive, and domestic effect can be as far as scarcity of products and bad distribution because those clan and oligarch groups enjoy monopoly or oligopoly systems where there is lack of competitors.

Furthermore, from history one can learn a good principle, that is: excessive liberalization is often a precursor of financial crises. The example can be given here, that is knickerbocker trust collapse in 1907 was a signal of a crises. And you should know that in that period, there are numerous trust which work as investment units but they are not banks, and there were lack of regulation for them. Similarly there are investment units with lack of regulation in 2007-2008 which then lead to financial turmoil. For simplicity, we include here a table (Table 1) to summarize some disadvantages related to excessive liberalization in a particular country, from the viewpoint of clan capitalism. Note that these results are 
often very different compared to benefits of excessive liberalism which neo-liberalism proponents often advertise and promote as receipt.

Table 1. Disadvantages of excessive liberalization from the viewpoint of clan capitalism

\section{Disadvantage of excessive liberalization \\ Oligopoly risk \\ Clan groups will pay incentive to their clan associate in democracy institutions}

Clan groups pay less tax rate

Reduce benefits for common people

Hidden opportunity cost

\section{Description}

There is tendency that clan groups will form oligopoly if there is not anti-trust or anticlan law enacted.

There is tendency that those clan groups or their oligopolistic association are more willing to pay more to their 'associates' in democracy institutions included law enforcement agencies in order they can continue their clandestine operations. Such practice is often found in a number of countries. This practice cannot be stopped without introducing special regulation. There is tendency that such oligopoly associations and clan groups expect a sort of benefits from influencing democracy institutions, especially tax collecting agents and law enforcement agencies, that is benefits in the form of lower tax rates, compared to what they actually ought to pay. Member of those clan groups expect that discounted tax rate as their benefit. In practice, excessive liberalization would mean less regulation, but that often would mean benefit only for larger clan groups. And common people will receive less benefit, especially because large clan groups will affect both market and democracy institutions alike to their advantages. Clan groups often play their role as middlemen and intermediaries who stay in the middle of a number of transactions type, including negotiation of certain projects, those practices can be found in number of countries including Japan, for example. In other word, both the buyer (user of a particular service) and the seller will pay more for those clan's services. That cost would imply a hidden opportunity cost. 


\section{Precursor of financial crises}

Other type of hidden opportunity cost is that those intermediaries often make a sale of piece of land or particular product become much higher more than necessary. Without specific regulation (such as botaiho), that kind of practice cannot be stopped. It is found that excessive liberalization is often a precursor of financial crises (see McKinnon for instance). Liberalization here also includes allowing excessive noise trading without any restriction whatsoever. Excessive liberalization often gives more advantage for clan groups to do trading with external clan without restrictions, including drug dealing and human-trafficking. Other restriction in terms of taxing of international foreign exchange market have been discussed elsewhere (Tobin tax) but no one can put that into practice.

Another problem in excessive liberalization is that there will be numerous noise traders which often create noises (fluctuation in prices) for their own advantages. We discuss this issue in the following lines.

Krugman have published a recent book on depression economics, the title of his recent book is: the return of depression economics[13]. A good chapter is devoted to history of America recession since 1907, exactly when knickerbocker trust collapse completely after failure to support numerous stock market trader, and they do not support anymore because of rush in their office that indicate that people lose their confidence in their scheme of investment (see page 156). And then you can compare that story of collapsing knickerbocker pseudobanking organization with Krugman's explanation of logic behind America recession in 2008, exactly because a number of investment company do similar risky investment including in secondary mortgage, stock market and also foreign exchange market (page 190), and they are not properly regulated just like knickerbocker trust in 1907, and that is indicating one hundred year cycle of crisis (1907-2007). And you should know that there are numerous pseudo-banking company in America who accept investment from their client (--exactly similar to what they call as 'trust' around one hundred year ago, see again page 156 of that book--), but they do not provide security nor they provide insurance if something happen to their client's investment, and don't you know that America always are reluctant to regulate those pseudo-banking system.

That is a good article to ponder if you are really really really really really a good economist without a cruel cruel cruel cruel cruel heart, that is because you will find that volatility is 
often caused by foreign exchange trader, which you can call as 'noise trader.' Don't you know that noise trader is everywhere, but there is no regulation at all especially to foreign exchange trader, as explained by Krugman in page 190:

'there were some calls for long-term restrictions on international capital flows, not just temporary controls in times of crisis. For the most part of these calls were rejected in favor of a strategy of building up large foreign exchange reserve that were supposed to stave off future crises. Now it seems that this strategy didn't work.' [13] p.190

And that is why: you should not believe to noise trader, and you should not lend your money to them too, because there is high likelihood that your investment money to them will disappear with probability chance more than $75 \%$, just as what happen with ltcm. Don't you know that noise trader is well defined by J.a. Frankel,[14] and noise traders can and are willing to create needless volatility and thereby force more risk-averse investors to stay away from marketplace. And that is the meaning of noise trader: they often create a number of gossip story in order a number of investment company collapse and then there will be huge market volatility.

\section{Concluding remarks}

One perhaps would think that a good idea to comprehend real situation behind economy of a given nation is to study the relation and interaction among the actors of such a clan capitalism. That is, to begin with network analysis instead of doing cumbersome mathematical analysis which mostly are based on unrealistic assumptions such as information symmetry, efficient market hypothesis, or the social utility of market exchange, or value of liberalization and privatization process.

Based on Amartya Sen's hypothesis, then one can extend further that hypothesize to become: (i) there is always tendency for clan groups to influence democracy system including news/media as the fourth pillar of democracy, in order to alter the course of distribution of resources for their advantage.

Survey summary: while the number of respondents are very low compared to what we initially expect, one can draw a rough summary with respect to perception of Russia economy at present days. Out of five respondents, $80 \%$ of which are below 26 years old, there are $60 \%$ of them who perceive that Russia economy is in bad condition, and government in general do not do their best to take care all people. $40 \%$ of the respondents think that government doing badly to take care all people, and the other think that Russia government doing very badly. But as to the living condition in their town, the perception diverse widely, as shown that $60 \%$ think that living condition is bad or very bad, and only $40 \%$ think that living condition in their town is good or very good. 
And to the question concerning what Russia government have to do, two respondents write that corruption should be vanished. And to improve living condition in their town, they suggest to do more on traffic, social programs, and to keep the face of the city.

We do not mention here other black market activities such as illegal import and export activities etc. which may or may not be related to clan group activities. Of course, if those activities in particular illegal importing or exporting of things related to drugs, then those activities are more likely related to clan groups. Limiting and decreasing plantation area of those plants which form as natural source of those illegal drugs can be effective (let say to decrease plantation area by $1-10 \mathrm{~km}^{2}$ per year), in this regards, but of course that would not be an easy task for law enforcement agencies in particular country, in particular because there are external market which include their own clans who are interested in those plants, and they already form connection with legal or illegal military forces (see diagram 5). That is why, one necessary step is to detach tentacles of those clans in government and military offices.

Apparently, more study on the extent and role of such clan capitalism in a nation's economy and also their role in globalized economy can be expected in the coming years.

\section{Acknowledgment}

Thanks to V. Kolbasina, G. Muftakhova, and others for responding to a questionnaire (see appendix I).

28 $8^{\text {th }}$ july 2010. Revised 1: $7^{\text {th }}$ aug 2010

url: http://www.sciprint.org

\section{Endnotes:}

[1] j. maggs (2009), “crony capitalism in america?" url:

http://veron.typepad.com/files/nationaljournal_090413.pdf

[2] S. Clarke, "globalization and the development of capitalism in russia," p.6, url:

http://www.nodo50.org/cubasigloXXI/congreso/clarke_10abr03.pdf 
[3] g. sharafutdinova (2007), "crony capitalism and democracy: paradoxes of electoral competition in Russia regions," working papers \#335, p.6,

http://kellogg.nd.edu/publications/workingpapers/WPS/335.pdf

[4] l. kosals (2006), "interim outcome of the Russian transition: clan capitalism," KIER, discussion paper no.610, url: http://src-h.slav.hokudai.ac.jp/pdf_seminar/060124kosals.pdf

[5] ICFAI business school, "banking crisis in Japan," p.4, url:

http://129.3.20.41/eps/get/papers/0411/0411001.pdf

[6] P. Hill (2003), "heisei yakuza: burst bubble and botaiho," SSIJ vol 6 no.1. url :

http://ssjj.oxfordjournals.org/cgi/reprint/6/1/1.pdf

[7] L. LaRouche (2009), Executive Intelligence Report, April 2009, vol 36 no.15, url:

http://www.larouchepub.com/eiw/public/2009/2009_10-19/2009_10-19/2009-15/pdf/48-

54_3615.pdf

[8] P.L. Luisi (2003) "autopoiesis, a review and a reappraisal," Naturwissenchaften 90, 49-59, http://www.lapetus.uchile.cl/lapetus/archivos/1208975754Autopoiesis,areviewandareappraisal. pdf. For autopoiesis analogy to economics situation, see for example bob Jessop.

[9] contrary to popular belief, andrei shleifer can be considered as close associate of russian clan (chubais). quote: "In a narrow sense Harvard mafia is the team of experts who disastrously advised the Russian government on capitalism in the 1990s. Engaged by the U.S. to show the Russians how the West controls corruption, the advisers became models of what to avoid...January 2006 article claims to show that "economics professor andrei shleifer, in the mid-1990s, led a Harvard advisory program in Russia that collapsed in disgrace." The article drew considerable criticism among shleifer's colleagues, collaborators, close friends, and students." source:

http://www.softpanorama.org/Skeptics/Pseudoscience/harvard_mafia.shtml

[10] M.I. Goldman (1996), "Why is the mafia so dominant in russia?" challenge vol. 39, quote: " Izvestiia on January 26,1994 , reported that the russian mafia now controls 70 to 80 percent of all private business and banking." source:

http://www.questia.com/googleScholar.qst;jsessionid=MRFB1GBB72KzLBNGptqvTsGcTwmC7sw5 L4dYTYND6cGJTTn28fTG!1798068544!162038653?docId=5000319091

[11] A. Goodman \& D. Goodman (2004), The exception to the rulers: exposing oily politicians, war profiteers and the media that love them. Hyperion Books. See in particular chapter 1 and 2. url: http://democracynow.org/book/

[12] Y. Kunio (1988), The rise of ersatz capitalism. For an example of the role of clandestine group in business operation, see a quote from his earlier article on this issue: "Yap Ah Loy's mines in Kuala Lumpur employed several thousand people. His business may qualify as the first Chinese capitalistic institution in the region, but the reason he was able to organize such a large scale operation is that he was the head of a secret society who resorted to violence for the protection and 
expansion of his business," Y. Kunio, "The rise of ersatz capitalism," source url:

http://repository.kulib.kyoto-u.ac.jp/dspace/bitstream/2433/56297/1/KJ00000131384.pdf

[13] P. Krugman (2009) the return of depression economics, w.w. norton and company, inc., new York. See p.156, 190.

[14] j.a. Frankel ( ), 'International capital mobility and exchange rate volatility,' URL: http://www.bos.frb.org/economic/conf/conf32/conf32f.pdf

[15] N.L. Khrushcheva (2006), "money and wealth in russia: politics and perception." international affairs working paper 2006.(p.58) source: url: http://www.gpia.info/files/u1/wp/2006-06.pdf

[16] V. Burgmann (2002), the cancer stage of capitalism and the politics of resistance. url: http://arts.anu.edu.au/sss/apsa/Papers/burgmann.pdf

[17] Le Corbusier and architecture of imperfection: url:

http://books.google.co.id/books?id=jaf0o5y780wC\&pg=PA178\&lpg=PA178\&dq=le+corbusier+arc hitecture+of+imperfection\&source=bl\&ots=cJNxsRtza0\&sig=OdV_MHvbg5e3EHvtw9w1czFaMr8\& hl=id\&ei=hrReTKmzJInEsA03zr2qCw\&sa=X\&oi=book_result\&ct=result\&resnum=1\&ved=0CBIQ6A EwAA\#v=onepage \&q=le\%20corbusier\%20architecture\%20of\%20imperfection \&f=false

[18] C.S. Marxsen (2005), “Russia in Olson’s template,” J. Comp. policy analysis: Research and Practice vol. 7 no.3, Routledge , url: http://www.unk.edu/uploadedFiles/facstaff/profiles/marxsenc/MarxsenJCPA7no3.pdf

url:

follow JesuS Christ only at http://www.twitter.com/guidetorepent http://guidetorepent.uphero.com/index.html http://guidetorepent.multiply.com http://message.diigo.com/user/guidetorepent

http://Guidetorepent.blogspot.com

http://findtheTruthnow.blogspot.com http://evangelismwithsocialmedia.blogspot.com http://www.esnips.com/web/Guidetorepent http://www.esnips.com/web/RepentanceGuide http://www.facebook.com/guidetorepent http://www.twitter.com/vChristianto 


\section{Appendix I response to a questionnaire}

In order to see whether the situation in Russia is getting better or not, a questionnaire have been sent to a number of people via online invitation, but alas there are only five respondents giving response to questionnaire sent to them (so far). Nonetheless this response can be considered as more or less reflecting frustrating situation experienced by common people. Respondents are Russian ordinary people or previously they stay in Russia, and the responses were given from last week in July 2010 until 5 Aug 2010.

The small survey was carried out online with the help of online survey form: http://www.surveymonkey.com/s/YBXNYJ8

Survey summary: while the number of respondents are very low compared to what we initially expect, one can draw a rough summary with respect to perception of Russia economy at present days. Out of five respondents, $80 \%$ of which are below 26 years old, there are $60 \%$ of them who perceive that Russia economy is in bad condition, and government in general do not do their best to take care all people. $40 \%$ of the respondents think that government doing badly to take care all people, and the other think that Russia government doing very badly. But as to the living condition in their town, the perception diverse widely, as shown that $60 \%$ think that living condition is bad or very bad, and only $40 \%$ think that living condition in their town is good or very good.

And to the question concerning what Russia government have to do, two respondents write that corruption should be vanished. And to improve living condition in their town, they suggest to do more on traffic, social programs, and to keep the face of the city.

We do not use advanced statistics here, we only present the commentaries and responses as is, and let the reader draw more insight from those answers.

1. Question: What is your present occupation?
a. College student. (20\%)
b. Teacher. $(20 \%)$
c. Scientist
d. Model
e. Musician
f. Other. (60\%)

2. Question: How old are you?
a. Less than 20 .
b. 21 to $25 .(80 \%)$ 

c. 26 to 35 .
d. 36 to 45 .
e. Above 46. (20\%)

3. Question: Do you you think that overall economy of Russia is good in the past few years? Give rate from 1-4 scale. (result is shown beside each choice)
a. Rate 1 (very good).
b. Rate 2 (good).
c. Rate 3 (bad). $\rightarrow(60 \%)$
d. Rate 4 (very bad). $\rightarrow(20 \%)$
e. I do not know. $\rightarrow(20 \%)$

Explanation: We have had no any economy - we just sale the gas only

4. Question: Do you think that government has done their best to take care all people? Give rate from 1-4 scale.
a. Rate 1 (very good).
b. Rate 2 (good).
c. Rate 3 (bad). $\rightarrow(40 \%)$
d. Rate 4 (very bad). $\rightarrow(60 \%)$
e. I do not know.
Explanation:

They did nothing

5. Question: Do you think that overall living condition in your town is better compared to ten years ago? Give rate from 1-4 scale.
a. Rate 1 (very good). $\rightarrow(20 \%)$
b. Rate 2 (good). $\rightarrow(20 \%)$ 
c. Rate 3 (bad). $\rightarrow(40 \%)$

d. Rate 4 (very bad). $\rightarrow(20 \%)$

e. I do not know.

Explanation:

prices grow up, but salary is the same

6. Question: According to a number of study (see for example: Mancur Olson, Power and Prosperity), the Russian economy is affected by crony capitalism or sometimes referred to as clan capitalism.
a. I strongly agree.
b. I agree.
c. I disagree. (25\%)
d. I strongly disagree.
e. I do not know. (75\%)

Answer:

(i) Our economy depends of prices for oil only and of what kind of Putin`s friends are in Government.

(ii) I am not familiar with the mentioned study and thus do not want to be too quick to either or agree or disagree with the statement.

7. Question: How Russia's economy can be improved in your opinion?

Describe what government can and should do to improve present economy.

Please explain.

Answer:

(i) The economy depends of sort of government. If this government is really voted by people, they will put money from selling gas, oil in to development of science, into very poor social problems, into private industry to help them. But, alas ...

(ii) corruption should be vanished 
(iii) It is impossible to sum it up in a few words, really.

(iv) They have to change their minds, i guess, cause all that they do is good only for someone's pocket, the first thing to do is to destroy corruption.

8. Question: Do you have other suggestion to improve overall living condition in your town?

Please explain.

Answer:

(i) In my town only? No, it depends of all country... The only I wish to our mayor is to safe, to keep the face of my town, of my very old and beautiful town, to not destroy it any more, for people could appreciate their history... And may be, it helps them to stay a good people.

(ii) They need to do something about the traffic.

(iii) In my opinion we need more social programs.

(iv) No.

9. Question: what is your hometown city?
a. Moscow. (75\%)
b. St. Petersburg.
c. Other. $(25 \%)$ 


\section{A comment on world population growth rate and World3 simulation*}

In the present article the writer discuss a number of alternative model of world population growth.

\section{Introduction}

Over the past few decades there is increasing concern among almost all scholars in the world, and especially environment scientist, economist, and system dynamics scientists alike, with respect to the population growth rate, and its impact to various global problems. Part of that concern is brought into public awareness through publication of Limits to Growth by meadows et al., around 1970s, and also its sequel with title Beyond the Limits.

While the simulation employed by Meadows et al. is based on system dynamics model developed by Forrester, and subsequently experts call that model as World3, an aspect which is often not considered important is that it has limitations and there are already critics on the model used. In this article, emphasis is given on such critics and limitation of limits to growth, and how a different population growth rate projection will lead to different conclusions.

First, we would like to mention that population growth projection conventionally uses an equation based on exponential growth of malthus [1]:

$$
N(t)=\frac{C}{(T-t)^{k}},
$$

Where: $\mathrm{C} \sim 1.8 \times 10^{11}, \mathrm{~T} \sim 2025, \mathrm{k} \sim 1$. It is interesting to note here that both in World3 dos program (the writer obtained their dos program from a colleague who received that program a number of years ago from $\mathrm{H}$. Bossel, a system dynamicist) and also none such reference is made in Limits to Growth concerning that exponential model, apparently because most modeler believe that such a model is the most realistic. But as we will explore further we will find that such an exponential growth is an over-estimate of the actual growth rate of world population. And while World3 already include feedback-loops as characteristics of system dynamics approach, one should realize that its basic model remains equation (1). This can be verified in World3 model which offers default limit of graphical presentation, ranging from 0 to $1.8 \times 10^{11}$ for population growth scale. That would imply that $\mathrm{C}$ parameter is used as the highest point of graphical presentation scale.

\footnotetext{
*V. Christianto, url: http://www.sciprint.org, email: VictorChristianto@gmail.com
} 
As we will discuss in subsequent section, that log-linear pattern can represent better the actual growth pattern of world population. This in turn can yield better projection.

\section{Critics to Limits to Growth}

Before we summarize critics to limits to growth, we will quote here a number of summarized conclusion of limits to growth, as described as follows:

Quoted from Limits to Growth [2]:

“...model we have constructed is, like every model, imperfect, oversimplified, and unfinished.

In spite of the preliminary state of our work, we believe it is important to publish the model and our findings now. (...) We feel that the model described here is already sufficiently developed to be of some use to decision-makers. Furthermore, the basic behavior modes we have already observed in this model appear to be so fundamental and general that we do not expect our broad conclusions to be substantially altered by further revisions.

Our conclusions are :

1. If the present growth trends in world population, industrialization, pollution, food production, and resource depletion continue unchanged, the limits to growth on this planet will be reached sometime within the next one hundred years. The most probable result will be a rather sudden and uncontrollable decline in both population and industrial capacity.

2. It is possible to alter these growth trends and to establish a condition of ecological and economic stability that is sustainable far into the future. ..."[2]

As to the critics to ltg (limits to growth), one can summarize as described as follows: [3]

"The most common criticisms of the original World3 model were that it underestimated the power of technology and that it did not represent adequately the adaptive resilience of the free market. Impressive - and even sufficient - technological advance is conceivable, but only as a consequence of determined societal decisions and willingness to follow up."[3]

\section{Conventional and non-conventional model of population growth rate.}

Second, let us take a look first at apparently similar growth rate, called the Moore's law for chip clock speed. But as nowadays the number shows that clock speed is not everything, 
then we focus on the number of transistor inside the semiconductor instead. The growth pattern of the number of transistor inside a semiconductor follows quite similar exponential growth rate. See figure 1 (table) and 2 (graphic plot).

\begin{tabular}{|c|c|c|}
\hline year & trans.no & speed of increase \\
\hline Y & $\mathrm{T}$ & SOI \\
\hline 1971 & 2300 & \\
\hline 1972 & 3500 & 1200 \\
\hline 1974 & 6000 & 1250 \\
\hline 1978 & 29000 & 5750 \\
\hline 1982 & 134000 & 26250 \\
\hline 1985 & 275000 & 47000 \\
\hline 1989 & 1200000 & 231250 \\
\hline 1993 & 3100000 & 475000 \\
\hline 1997 & 7500000 & 1100000 \\
\hline 1999 & 9500000 & 1000000 \\
\hline 2000 & 42000000 & 32500000 \\
\hline 2002 & 55000000 & 6500000 \\
\hline 2004 & 291000000 & $1,18 \mathrm{E}+08$ \\
\hline 2007 & 582000000 & 97000000 \\
\hline 2008 & 820000000 & $2,38 \mathrm{E}+08$ \\
\hline
\end{tabular}

Figure 1. No of transistor as function of year

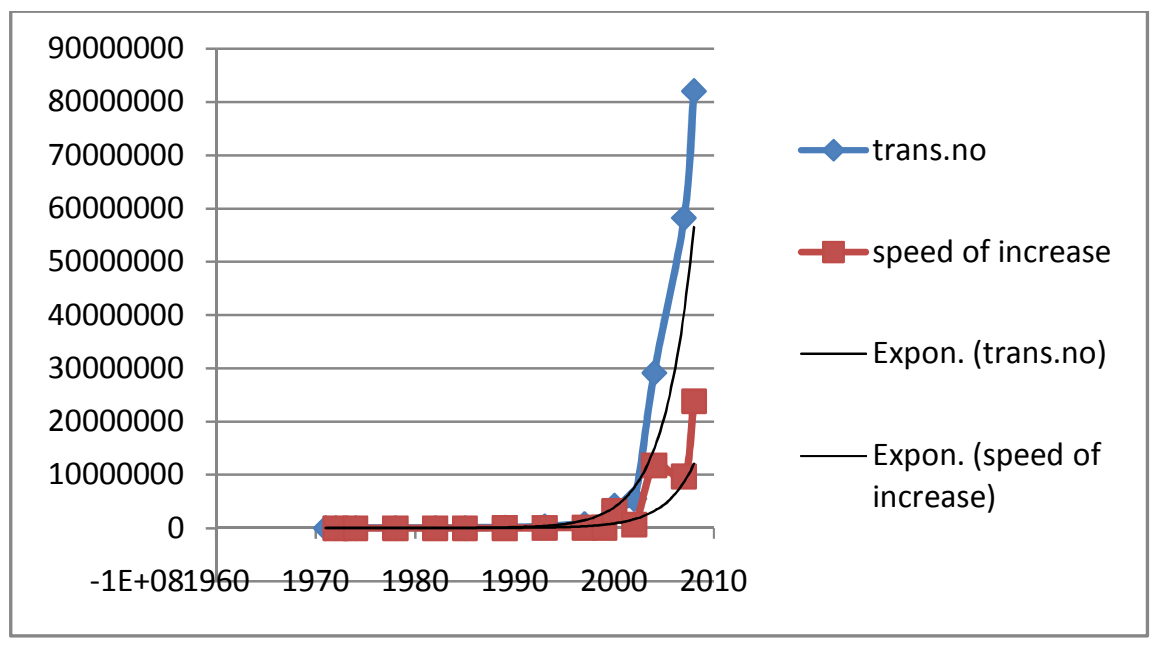

Figure 2. No of transistor grow exponentially. 
But we can simplify further the graphical plot, by transforming the data to become log-log plot. The result will shown quite exactly a loglinear growth pattern. See figure 3 (table, log $\log$ ), and figure 4 (log $\log$ plot). Perhaps we can say that no. of transistor in a semiconductor follows a loglinear-Moore's law instead of standard Moore's law.

\begin{tabular}{|c|c|c|}
\hline year & trans.no & speed of increase \\
\hline $\log Y$ & $\log T$ & log SOI \\
\hline 3,2947 & 3,36173 & \\
\hline 3,2949 & 3,54407 & 3,0792 \\
\hline 3,2953 & 3,77815 & 3,0969 \\
\hline 3,2962 & 4,46240 & 3,7597 \\
\hline 3,2971 & 5,12710 & 4,4191 \\
\hline 3,2978 & 5,43933 & 4,6721 \\
\hline 3,2986 & 6,07918 & 5,3641 \\
\hline 3,2995 & 6,49136 & 5,6767 \\
\hline 3,3004 & 6,87506 & 6,0414 \\
\hline 3,3008 & 6,97772 & 6,0000 \\
\hline 3,3010 & 7,62325 & 7,5119 \\
\hline 3,3015 & 7,74036 & 6,8129 \\
\hline 3,3019 & 8,46389 & 8,0719 \\
\hline 3,3025 & 8,76492 & 7,9868 \\
\hline 3,3028 & 8,91381 & 8,3766 \\
\hline
\end{tabular}

Figure 3. table depicting log of year and log of transistor number in a semiconductor

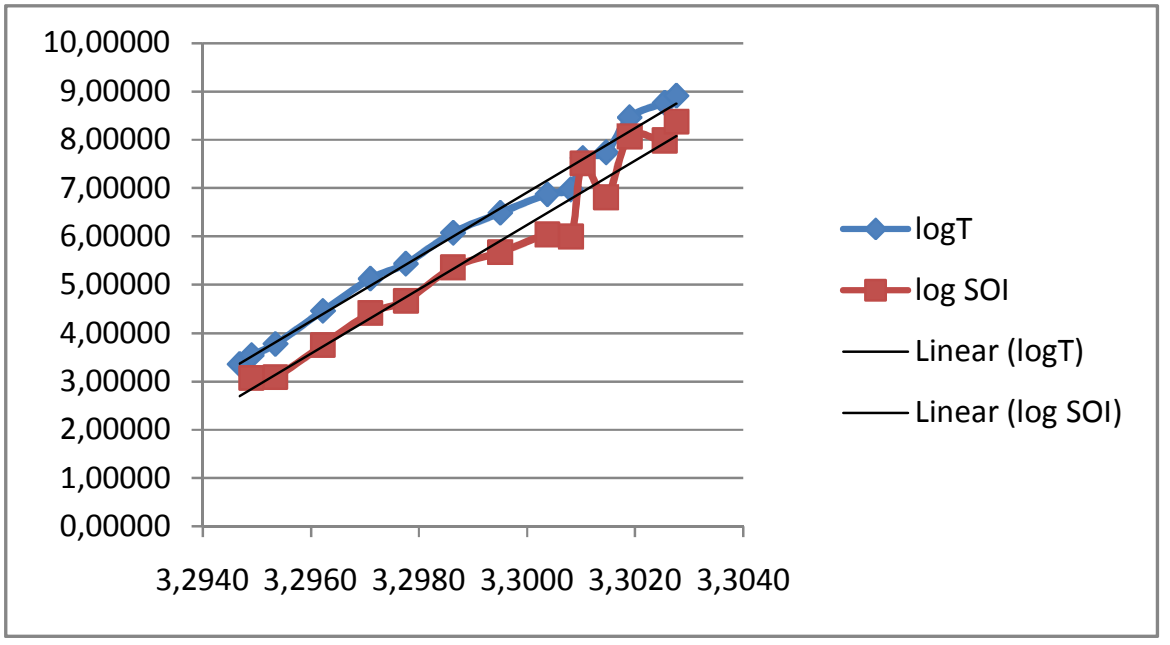

Figure 4. log-log plot of number of transistor in a semiconductor and log of year 
Now we turn our attention again to equation (1).

The commonly used model (1) has significant drawback, that is that it implies that there will be very large increase in 2025, as (T-t) approaches zero, which seems to be unlikely, furthermore it yield projection of world population significantly exceed 2005 value, because the six-billionth human was born around 2005, and the model (1) over-estimate projection significantly.

Other improvement of this conventional model is discussed in ref. [4], based on refinement by Kapitza, which can be summarized as follows:

$$
\frac{d N_{E}}{d t}=\frac{C}{(T-t)^{2}+\tau^{2}}=\frac{C}{(T-t)^{2}+45^{2}},
$$

Where T is now revised to be 2026, instead of 2025 in [1]. A slight difference.

Another model that looks interesting is the sinusoidal equation as follows:

$$
\frac{d N_{E}}{d t}=\frac{r}{\gamma} \sin ^{2} \frac{2 N_{E}}{r}
$$

Where $\mathrm{r}$ and $\gamma$ are adjustable parameters. After some numerical fitting, one finds the following value: 0.4 and 0.000005 , respectively. As shown in ref. [4], the result can be interpreted as signal of phase transition, instead of dynamics crossover, as indicated in World3 simulation package.

Furthermore, one can expect similar loglinear pattern using equation (2) and equation (3), but not for equation (1). And again, equation (1) exceeds the observed world population number around $6 \times 10^{\wedge} 9$ at 2005 , that is why one can begin to question validity of using equation (1) to make reliable estimate of world population growth.

See figure 5 and 6, for graphical plot comparing eq. (1) , (2) and (3). While figure 7 and 8 depict the table and graphical plot for the same equations, but in log-log scale. It should be clear that loglinear growth pattern appear more precise to represent the world population growth. In the following figure (5) and (6), F1, F2, and F3 represent equation 1, 2, 3 respectively. To calculate projection based on equation 2 and 3, one should begin with an assumption on the value of No. In this model, we begin with year 2000, therefore $\mathrm{N} 0=\mathrm{N}(2000)$, and then we adjust the value of No such that $\mathrm{N}(\mathrm{t})$ for $\mathrm{N}(2005)=6000$, that is six billions population in 2005 . Other population number are also in million scale.

$$
N(t)=N_{i-1}+\frac{d N_{i}}{d t}=N_{i-1}+\frac{C}{\left(T-t_{i}\right)^{2}+45^{2}},
$$




$$
N(t)=N_{i-1}+\frac{d N_{i}}{d t}=N_{i-1}+\frac{r}{\gamma} \sin ^{2} \frac{2 N_{i}}{r}
$$

Thus we obtain that $\mathrm{N}(2000)=5650$ for $\mathrm{F} 2$, and $\mathrm{N}(2000)=5350$ for F3. Then for F3 we also should adjust two more parameters in order to reach $N(2005)=6000$.

\begin{tabular}{|rrrrr|}
\hline \multicolumn{1}{|l}{ yr (>00) } & F1 (in mio.) & F2 (in mio) & \multicolumn{1}{l|}{ m3 (in) } & Actual \\
2000 & 6923,077 & 5650 & 5350 & \\
2001 & 7200,000 & 5717,925 & 5473,010 & \\
2002 & 7500,000 & 5787,129 & 5600,824 & \\
2003 & 7826,087 & 5857,606 & 5733,662 & \\
2004 & 8181,818 & 5929,348 & 5871,750 & \\
2005 & 8571,429 & 6002,341 & 6015,322 & 6000 \\
2006 & 9000,000 & 6076,568 & 6164,615 & \\
2007 & 9473,684 & 6152,008 & 6319,873 & \\
2008 & 10000,000 & 6228,636 & 6481,341 & \\
2009 & 10588,235 & 6306,423 & 6649,264 & \\
2010 & 11250,000 & 6385,336 & 6823,886 & \\
2011 & 12000,000 & 6465,336 & 7005,449 & \\
2012 & 12857,143 & 6546,381 & 7194,182 & \\
2013 & 13846,154 & 6628,423 & 7390,308 & \\
2014 & 15000,000 & 6711,410 & 7594,030 & \\
2015 & 16363,636 & 6795,287 & 7805,530 & \\
2016 & 18000,000 & 6879,993 & 8024,964 & \\
2017 & 20000,000 & 6965,463 & 8252,455 & \\
2018 & 22500,000 & 7051,629 & 8488,082 & \\
2019 & 25714,286 & 7138,418 & 8731,879 & \\
2020 & & 7225,754 & 8983,822 \\
2021 & & 7313,559 & 9243,826 & \\
2022 & & 7401,751 & 9511,731 & \\
2023 & & 7490,246 & 9787,300 & \\
2024 & & 7578,960 & 10070,213 & \\
& & & & \\
\hline
\end{tabular}

Figure 5. World population projection with three different equations 


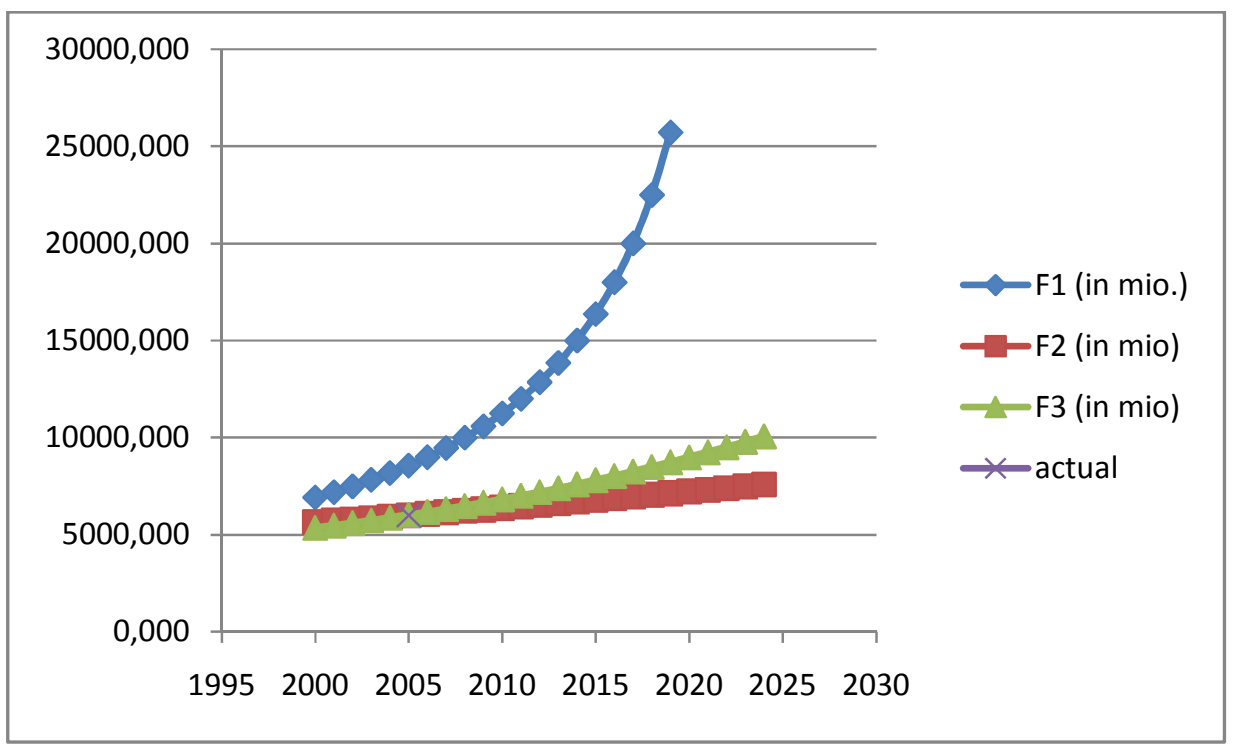

Figure 6. Graphical plot of world population projection with three different equations

$\log \mathrm{F} 1$ versus $\log \mathrm{yr}$

\begin{tabular}{|rrrrr|}
\hline \multicolumn{1}{l}{ log $\mathbf{y r}$} & \multicolumn{1}{l}{ logF1 } & & & \\
$(\mathbf{2 0 0 0 )}$ & (mio.) & logF2 (mio) & logF3 (in) & Actual \\
3,30103 & 3,840 & 3,7520 & 3,7284 & \\
3,301247 & 3,857 & 3,7572 & 3,7382 & \\
3,301464 & 3,875 & 3,7625 & 3,7483 & \\
3,301681 & 3,894 & 3,7677 & 3,7584 & \\
3,301898 & 3,913 & 3,7730 & 3,7688 & \\
3,302114 & 3,933 & 3,7783 & 3,7793 & 3,778151 \\
3,302331 & 3,954 & 3,7837 & 3,7899 & \\
3,302547 & 3,977 & 3,7890 & 3,8007 & \\
3,302764 & 4,000 & 3,7944 & 3,8117 & \\
3,30298 & 4,025 & 3,7998 & 3,8228 & \\
3,303196 & 4,051 & 3,8052 & 3,8340 & \\
3,303412 & 4,079 & 3,8106 & 3,8454 & \\
3,303628 & 4,109 & 3,8160 & 3,8570 & \\
3,303844 & 4,141 & 3,8214 & 3,8687 & \\
3,304059 & 4,176 & 3,8268 & 3,8805 & \\
3,304275 & 4,214 & 3,8322 & 3,8924 & \\
3,304491 & 4,255 & 3,8376 & 3,9044 & \\
3,304706 & 4,301 & 3,8429 & 3,9166 & \\
3,304921 & 4,352 & 3,8483 & 3,9288 & \\
3,305136 & 4,410 & 3,8536 & 3,9411 & 3,9535 \\
3,305351 & & 3,8589 & 3 &
\end{tabular}




\begin{tabular}{|lll|}
3,305566 & 3,8641 & 3,9659 \\
3,305781 & 3,8693 & 3,9783 \\
3,305996 & 3,8745 & 3,9907 \\
3,306211 & 3,8796 & 4,0030 \\
\hline
\end{tabular}

Figure 7. World population projection with three different equations (in log-log scale)

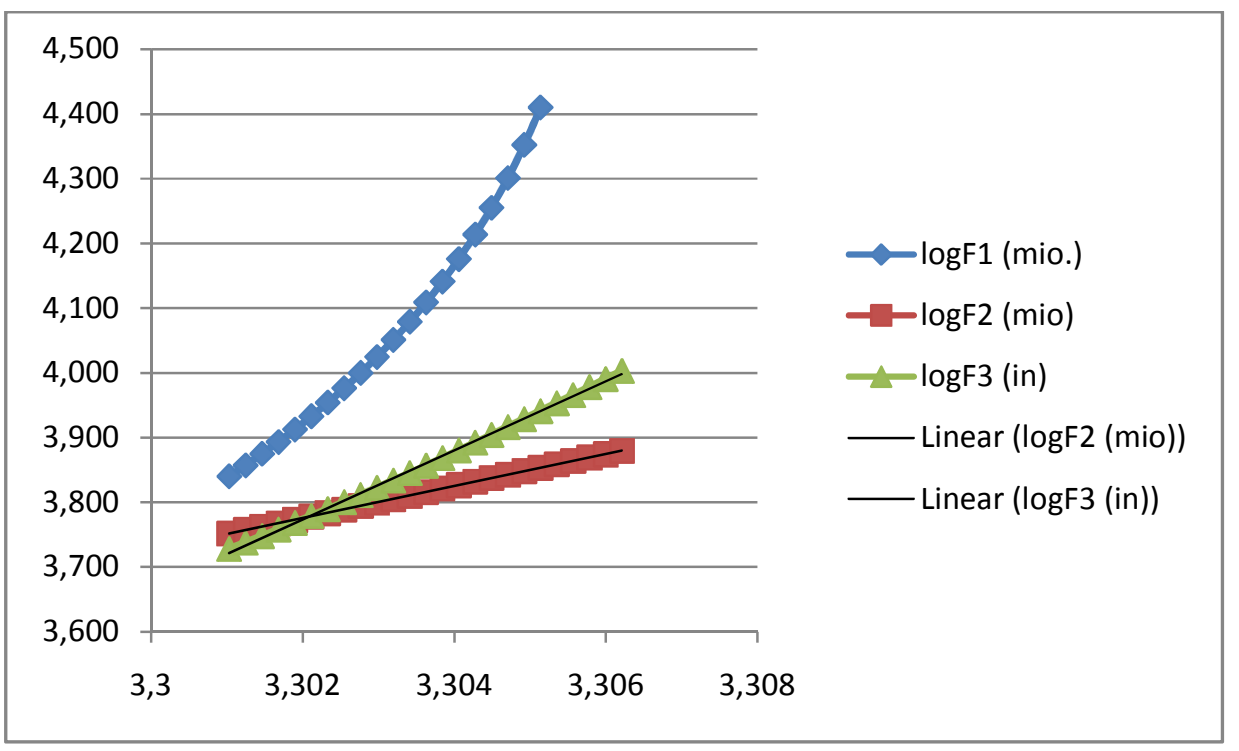

Figure 8. Graphical plot of world population projection with three different equations (in $\log \log$ scale)

We can remark here that the above model can be extended to include feedback-loop for precision, but that can be developed further, because the purpose of the graphical plot above is to find out whether there are other plausible models for world population projection.

\section{Why you ought not to use some vaccination for depopulation}

Apparently as a result of the above overestimate of world population growth, there are a number of alarmist effect, including suggestion to do depopulation, which is another name of soft-termination of a number of people, both using negative-check measures, or using positive check measures (in malthusian language). We discuss here a recent issue, that is public speech by bill gates concerning his program to do depopulation using vaccination program in number of developing countries. From the viewpoint of the world population 
projection as discussed above, such a drastic measure based on exaggerated model appear too ridiculous.

A number of reputable scientist and not less than bill gates seem to think that reducing population (depopulation) significantly can solve unwanted global heating,[5] that is that reducing population can be a good solution of the problem of $\mathrm{CO} 2$ emission. His argument is that $\mathrm{CO} 2$ emitted by human being is the primary culprit of unwanted heating of the globe, therefore his argument is continued with reasoning that for reducing such an unwanted heating, then human $\mathrm{CO} 2$ emissions should be drastically reduced, and for doing so: then human population should be reduced systematically. His formula, as he explained in February 2010 in a public speech, can be simplified as follows: $\mathrm{CO} 2=\mathrm{P} \times \mathrm{S} \times \mathrm{E} \times \mathrm{C}$, where C02, P, S, E, C each represent projected totally humanly-emitted carbondioxide, population number, average number of services per person, and the average amount of energy units per service, and the average $\mathrm{CO} 2$ emitted load per unit of service per year, respectively.

There are a number of video clips which you can easily found in youtube or elsewhere, which summarize his presentation. For example, see the following urls: http://www.youtube.com/watch?v=CcBKLhWY9is

And what about his method? Now that seem not too surprising, given that he has been quite active to support vaccination via his charitable foundation. Of course, that would not mean that he want to do reduce present population with vaccination, what he aims to do is to reduce the growth rate of world population.

To summarize, such a drastic measure can be viewed as side effect of publication of ltg (limits to growth). The study is based on finite earth hypothesis, and its primary argument is more or less as follows: as energy and other resources continue to be more scarce in 21th century, then at a point there would be real problem imposed by human population, which need to be addressed drastically. Limits to growth give a hundred year projection based on their model called World3, then they conclude that such a simulation give projection that unless the world take drastic measure, then before one hundred year from 1970s, human beings will find great problems. Since then there are increasing movement towards addressing human population in drastic measure.

Some of the reader would argue then that supporting depopulation program is not the same with terminating present population, because the measure actually is vaccination or other measures intended to reduce population growth rate. But for you to know that among those elite groups, there are plan to take both drastic measures, i.e. reduce growth rate of population to zero growth (negative checks), and also to reduce present population drastically (positive checks, in malthus language). 
While solving natural resources depletion remain an open problem, one perhaps can recall that no matter what happen, reducing $90 \%$ human population in the name of humanbeings survival in this planet is not a legitimate policy. But that is exactly what some leading environmentalist aim to do[6]. And once again we can remark that World3 is based on population projection which is not realistic compared to present growth of world population. Hopefully government and policy makers all over the world can make up their mind concerning this issue, and stop doing depopulation, especially to foreign countries.

For other critics concerning the use of computer simulation, see [7] for instance.

\section{What is world humanitarian forum and club of rome}

For you to know: world humanitarian forum is part of club of rome activities. quote: "Mr. Walter Fust, Director General of the World Humanitarian Forum"[9].

The main theme of club of rome is quite clear, that is they demand that: "radical measures must be taken urgently to avert the risks of runaway climate change and ecosystems collapse."[9] What they mean with radical measures include excessive and massive depopulation policy including devastating a number of countries, which they think are beyond control, including but not limited to el salvador.

Quote: "According to an NSC spokesman, Kissinger initiated both groups after discussion with leaders of the Club of Rome during the 1974 population conferences in Bucharest and Rome. The Club of Rome, controlled by Europe's black nobility, is the primary promotion agency for the genocidal reduction of world population levels. The Ad Hoc Group was given "high priority" by the Carter administration, through the intervention of National Security Adviser Zbigniew Brzezinski and Secretaries of State Cyrus Vance and Edmund Muskie. "[8]

Their main character is typical of destructionists, that is those people who think that they can develop and build after they destruct a number of countries (that is to "develop through destruction"). quote: "the financial crisis and the consequent economic slowdown provide an exceptional opportunity to restructure economic and financial systems so as to achieve new patterns of environmentally sound."[9]

See also a pseudo-lecture in [10], how population is seen as major problem, and therefore massive depopulation is their opt choice to solve. That is the character of global depopulation policy promoted by the club of rome, world humanitarian forum, and global humanitarian forum. This project they call as "a new international humanitarian order," apparently as a new terminology of NWO (new world order). 
The characters of the message by those global pseudo-leaders who are almost all of them industrial leaders, are not so different from the message from nobel for peace summit in nov. 2009, [11] with exception that in the nobel for peace laureates' message there is no specific mention of "depopulation policy" as solution of global problems.

\section{Concluding remarks}

We discuss shortly a number of alternative model of world population growth. Two alternative models considered here yields a new observed pattern that is log-linear growth pattern, and they appear quite insightful to suggest as better population projection compared to the standard exponential growth based on malthus. One can even begin to compare with other growth pattern, that is growth of no. transistor in a semiconductor, which also follows log-linear growth, that is why perhaps a better name for that pattern is log-linear Moore's law.

While the simulation employed by Meadows et al. is based on system dynamics model developed by Forrester in MIT, and subsequently experts call that model as World3, it is often not considered important that it has limitations and there are already critics on the model used. In this article, emphasis is given on such critics and limitation of limits to growth, and how a different population growth rate projection will lead to different conclusions.

While solving natural resources depletion remain an open problem, one perhaps can recall that no matter what happen, reducing $90 \%$ human population in the name of humanbeings survival in this planet is not a legitimate policy. But that is exactly what some leading environmentalist aim to do[6]. And once again we can remark that World3 is based on population projection which is not realistic compared to present growth of world population. Hopefully government and policy makers all over the world can make up their mind concerning this issue, and stop doing depopulation, especially to foreign countries.

For other critics concerning the use of computer simulation, see [7] for instance.

Mid of aug 2010, revised 29th aug. 2010

VC, url: http://www.sciprint.org 


\section{Endnotes:}

[1] Karev, G.P. (2005), "dynamics of inhomogenous populations and global demographic models," p.2 in arXiv:physics/0505039

[2] source: url: http://www.propagandamatrix.com/archive_club_of_rome.html

[3] source: url: http://www.sublimeoblivion.com/2010/02/16/review-ltg/

[4] Golosovsky, M. (2009), "models of the world human population growth - critical analysis," p.2-4 in arXiv:physics.soc-ph/0910.3056

[5] quote: "The depopulation plan is supported by the world's wealthiest people, including Bill Gates, who admittedly funds vaccinations to reduce global populations by $10-15 \%$. Leading population planners and economic developers advance identical plans to cull the world's population to 1 billion. ... requires planning and an unprecedented conspiracy to commit genocide by applying advances in genetic biotechnologies exclusively available and affordable to drug companies controlled by the investment bankers," Dr. Horowitz adds." Source url: http://jennyhatch.com/2010/05/09/profitable-depopulation-plot-links-jp-morgan-chase-andgoldman-sachs-to-vaccination-contaminations-and-bigpharma-corruption/

[6] LaRouche, L. (2009), Executive Intelligence Report, April 2009, vol 36 no.15, url: http://www.larouchepub.com/eiw/public/2009/2009_10-19/2009_10-19/2009-15/pdf/4854_3615.pdf

[7] Imhof, P., (2006), "computer simulation in the controversy over limits to growth," url: http://doku.b.tu-harburg.de/volltexte/2006/172/pdf/RR4.pdf

[8] anonymous, "world depopulation is top NSA agenda: club of rome," http://educateyourself.org/nwo/nwopopcnsaglobal2000report10mar81.shtml

[9] http://www.clubofrome.org/eng/meetings/vienna_2009/

[10] club of rome: inching towards peace, http://www.clubofrome.at/news/sup2009/dl_dec_hrh.pdf

[11] quote: "Franz Josef Radermacher from the Club of Rome and Global Marshall Plan initiative, Ian Dunlop from the Club of Rome," URL: http://www.nobelforpeacesummits.org/final-conference-statement-10th-world-summit-2/ 
url:

follow Jesus Christ only at http://www.twitter.com/guidetorepent

http://guidetorepent.uphero.com/index.html

http://guidetorepent.multiply.com

http://message.diigo.com/user/guidetorepent

http://Guidetorepent.blogspot.com

http://findtheTruthnow.blogspot.com

http://evangelismwithsocialmedia.blogspot.com

http://www.esnips.com/web/Guidetorepent

http://www.esnips.com/web/RepentanceGuide

http://www.facebook.com/guidetorepent

http://www.twitter.com/vChristianto 


\title{
On the Relation between Mathematics, Natural Sciences, And Scientific Inquiry
}

\author{
V. Christianto, http://sciprint.org, email: admin@sciprint.org \\ Florentin Smarandache, smarand@unm.edu
}

In this article, we will shortly review a few old thoughts and recent thoughts on the relation between Mathematics and the Natural Sciences. Of course, the classic references to this open problem will include Wigner's paper (1964); a more recent review article is Darvas (2008). But it appears that this issue is partly on the domain of natural philosophy and also philosophy of inquiry. Therefore we will begin with a review on some known thoughts of Kant, Bacon, Popper, etc.

Our hope here is to find out clues to reveal the hidden structure of Nature, just as what Planck did a century ago. (An early note to our scientific colleagues: In writing this article we choose to switch off our role as 'practical scientist' and switch on the 'free thinker' mode, therefore you can sit back and relax, because chance is what we write here is not related to what you're doing; this is more on science as a whole. But of course if you're interested in this kind of article, you can read on.)

In the meantime, we've written a rather serious article on this issue, but after midnight our thought becomes twisted, and now we are going to rewrite it again in the style of Scott Adams' Dilbert comics. This belongs to our favorite comic strips. If at certain point you feel like we're going too far (probably saying to yourself: Heck, what kind of tablets these guys have swallowed?), perhaps you should stop reading or send this file to recycle bin. Otherwise, you can continue reading and make up your mind later on.

\section{The Hidden Structure of Nature: What it is, what it was}

It appears as a fair guess to say that the greatest Natural philosopher was Kant. One of his most cited remark is perhaps the distinction between 'phenomena' and 'noumena' (from 'nous'). To put this idea a bit simpler, we can say that phenomena refer to processes or symptoms that appear to the eyes, while noumena refer to the hidden configuration or inner structures which are beyond what meet the eyes.

But that notion of 'noumena' is quite problematic, because it does not clarify how 'hidden' or which deeper level that we're looking for. If for instance, we discuss here the elementary particles, then does it mean that present hadron physics theories or strong forces already reflect the noumena, or shall we find out hidden structure beyond the hadrons, perhaps something like sub-quark or Planck scale models? 
In this regards, some physicists already mention that there is a scale invariance character of elementary particles, which suggests that we can always reveal new structure at deeper and deeper scale. Perhaps it is quite safe to say that the restriction here is not on theoretical side, but more on the precision of measurement apparatus.

If in accordance with Kant the phenomena are qualitatively distinct from the 'noumena' (the hidden structure of Nature), then problem of finding <noumena $>$ will be more adverse if we ask not only what Nature is today, but also what Nature was in the past. In this regards, it is quite apparent that the uncertainties of the problem become twofold, one concerns the deep structure of Nature itself, and the next concerns the premise of the smooth continuation of time.

Most evolution theories apparently are based on this premise of a smooth progression of things (some modern models are based on dynamical equation like Lotka-Volterra equation, but how to define time itself remains an open issue). On the other side, there are new theories based on possibility of 'sudden changes' happening on large scales, for instance the concept self-organized criticality introduced by Per Bak et al., emergence theory, spontaneous symmetry breaking, etc. (Darvas 2008).

In such a model based on the self-organized criticality, sudden changes can happen after a long period of stasis. For example, consider a pile of sand: initially it can pile up almost vertically, until sometime it will change such that a slope will form what is known as 'critical angle' (see Figure 1).

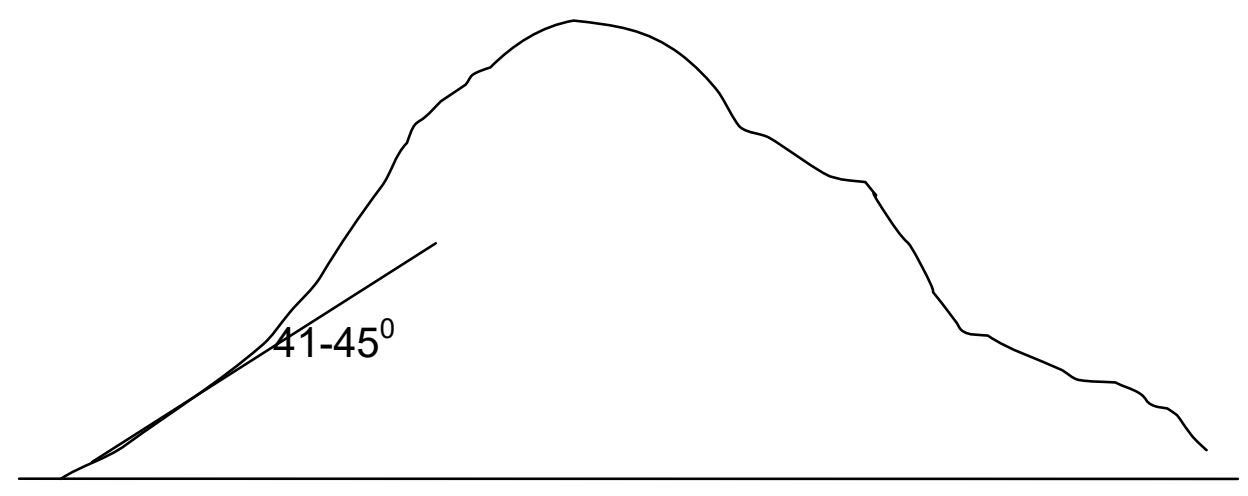

Figure 1. Sudden change to form critical angle.

Hopefully the above example can give illustration how the sudden changes can happen during such critical phenomena. Various other critical phenomena can be related to this self-organized criticality, so that it is quite problematic to conceive how smooth 
continuation of changes can take place 'naturally'. Another well-known example is the geological layering formation near Yukatan area, Mexico. As reported by Alvarez et al., they indicate some kind of periodic changes in the past at the order of thousand years.

Nowadays, the self-organized criticality phenomena have been studied extensively in various context; for a quick look see for instance Boldyrev (arXiv:hep-th/9610080), and Ambjørn, Jurkiewics \& Loll (arXiv: hep-th/0712.2485, gr-qc/0711.0273). One can also find that introducing the discontinuous progression of 'time' will lead to a quite different Galilean law of motion, and so forth.

One can also note here that in some ancient thinking, large natural changes can take place in the same time with large social upheavals. From the viewpoint of modern dynamics theory, whether such a large climate or environmental change really can affect social upheaval remains mystery, although there has been study on the relation between human/population evolution processes and their environment (by T. Barnosky from Berkeley Univ.). From a viewpoint, this may explain why some people feel that they can predict anything except to predict when the sky would fall upon them (remember the Asterix comics, for instance).

Nonetheless, we should limit our discussions here on self-organized criticality only in the domain of Natural phenomena. Meanwhile, other people may find that those sudden changes may also be related to Kuhn's idea of 'paradigm changes' in the history of science (Gholson \& Barker, 1985). For example, one can notice from history of modern science that the long-stagnant period between Planck's blackbody radiation (1901) until 1921 was a precursor to the rapid development in short period (1922-1928), where the modern Physics began. As Weinberg once remarked such a rapid change is so remarkable in history such that scientists nowadays refer to 'Classical Physics' for all things happened before this era. Nonetheless, in this article we don't discuss such a possible parallelism any further.

\section{On the Methods of Inquiry: From Bacon, Popper, to Habermas}

As the night goes very late, now we will continue this rambling note on how scientists may possibly discover something new in their fields. In this section, it is safe to say that you can forget all what you already learned on scientific methods, because this section is not about that classic teaching on science. This section is more about where to begin the scientific process itself. As we all know, how to invent and how to discover are perhaps one of the most fundamental questions for all living scientists (including physicists). In writing this section we would rely solely on a few irrelevant experiences with pets and also to a crystal ball which tells nothing.

It seems worth to mention here Darvas' (2008) note on the distinctive standpoints between Bacon, Polanyi and Popper. Bacon emphasized methodological processes which should be given attention in science; somewhat a more philosophical part of what Galileo did experimentally. 
In the mean time, Polanyi gave emphasize on the 'personal knowledge.' By personal here he meant human mind which consists of things he/she learnt (objective knowledge), things he/she thought (tacit knowledge), and also things he/she perceived (subjective knowledge). In other words, according to Polanyi, one's personal knowledge does not necessarily mean to be always subjective, though it may include subjective knowledge.

Karl Popper who wrote his seminal book 'Objective Knowledge' apparently as a response to Polanyi's book 'Tacit Knowledge' disagreed strongly with this idea of personal knowledge. Popper himself apparently emphasized the role of knowing 'episteme', via continuing criticism. In his model, validation of theory is not possible to achieve via experiments, they can only support or reject a hypothesis. For further discussion on this issue, see Darvas' review (2008).

We can make further remark here that Polanyi's assertion of personal knowledge and tacit knowledge today has begun to be implemented in the so-called Knowledge Management. This is a modern method to organize the unstructured parts of human knowledge, for instance see the OneNote feature in recent version of MS Office.

In the context of Knowledge Management, one can predict that in the future our present methods of file management will be improved to enable people organize better their tacit knowledge. For instance, scientists perhaps would prefer to organize their files according to their specific 'mind-mapping' diagram, instead of standard 'vertical' folder systems. The distinction is shown in Figure 2 and Figure 3 below.

\begin{tabular}{|c|c|c|c|}
\hline 23 & $\begin{array}{l}\text { Picture } \\
\text { Add a picture from your computer } \\
\text { or from somewhere else on the } \\
\text { web. }\end{array}$ & & $\begin{array}{l}\text { Text } \\
\text { Add some words to: } \\
\text { a welcome message } \\
\text { text editor. }\end{array}$ \\
\hline & ADD TO BLOG & & ADD TO BLOG \\
\hline \multirow[t]{2}{*}{ 可囯 } & $\begin{array}{l}\text { HTML/JavaScript } \\
\text { Add third-party functionality or } \\
\text { other code to your blog. }\end{array}$ & \begin{tabular}{|l|l|}
5 \\
5
\end{tabular} & $\begin{array}{l}\text { AdSense } \\
\text { Display AdSense ads } \\
\text { your blog. }\end{array}$ \\
\hline & ADD TO BLOG & & ADD TO BLOG \\
\hline \multirow[t]{2}{*}{$\equiv$} & $\begin{array}{l}\text { Feed } \\
\text { Add content from a site feed to } \\
\text { your blog. }\end{array}$ & $=$ & $\begin{array}{l}\text { Labels } \\
\text { Show all the labels o } \\
\text { blog. }\end{array}$ \\
\hline & ADDTORIOG & & ADD TORIOG \\
\hline
\end{tabular}

Figure 2. The common File/Information structure. 


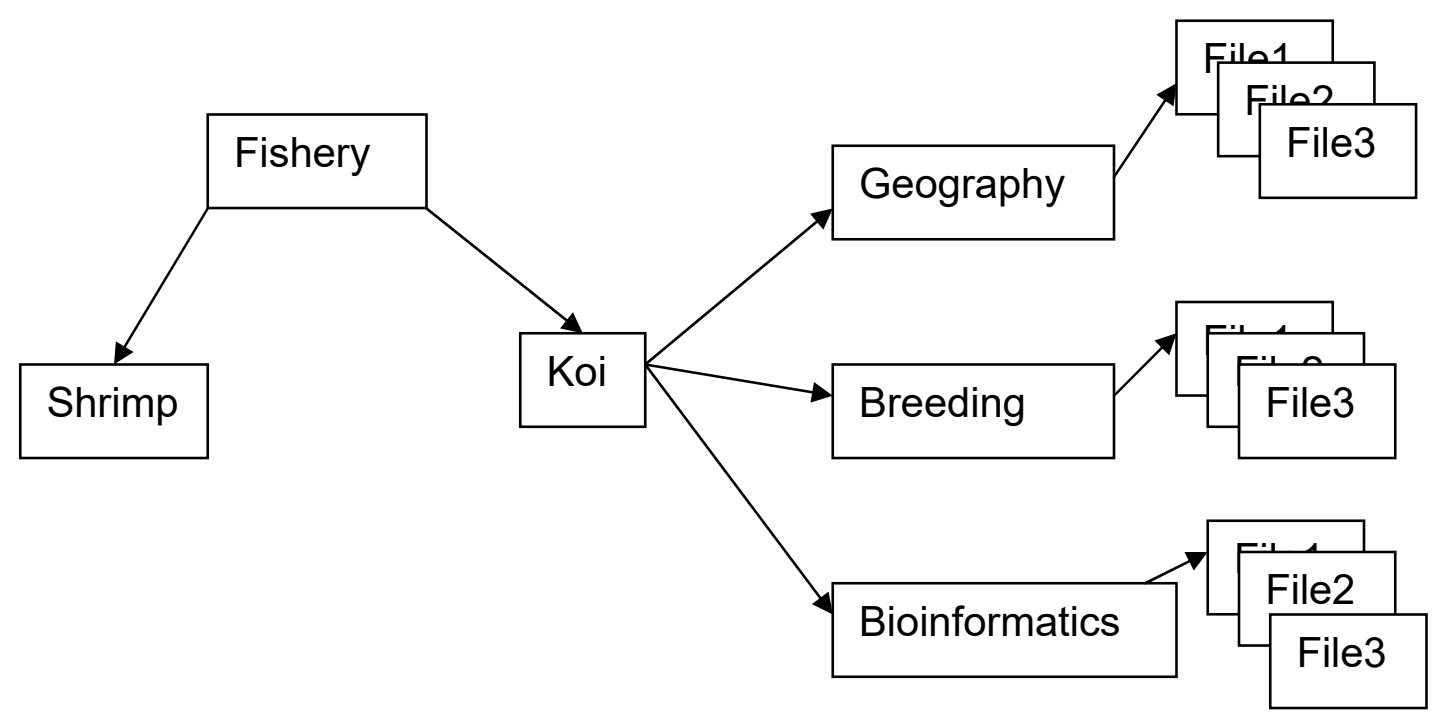

Figure 3. Mind-map diagram and file management

It is clear that mind-map diagram enables the users to track his/her files according to his/her interests, because most people think visually. Of course, the present method to organize files (folders etc), which is based on cabinet system around 1950s, can be retained, provided they can be integrated with the visual/mindmap approach.

Now we discuss some recent thoughts on scientific programs. Meanwhile, Jurgen Habermas, a leading philosopher from the Frankfurt School, opened a whole new can of worms outside of this traditional debate on the 'objectivity of science.' He suggests a quite different argument compared to Popper's objective science. First, we can refer to Lakatos' idea (see Gholson \& Barker, 1985) of 'scientific program,' i.e. the progress of scientific development was actually determined by a group of respective scientists in each area, who also would write recommendations to the governments. While this standard practice is quite common in the most developed countries, especially after the WWII, it has been pointed out by Habermas (1968) that in this respect the scientific development programs themselves are not free of interests, ranging from industrial interests, a country's economics preservation, energy interests, and so on. This is not to say that this practice is wrong by itself, but it is to indicate that it becomes quite difficult to describe these programs as 'objective knowledge', at least in the sense of those ancient Greek scholars who seek knowledge as part of their effort to understand the Logos.

In Habermas' view, it is impossible to perceive that modern sciences follow the same path of these ancient Greek scholars, because in today's modern world, the Logos disappears and it is replaced with 'scientific programs.' To put in other words, what we 
study in modern days are not BioLogos, but perhaps BioPrograms, not ZooLogos but ZooPrograms and so on. For example, in Bacon's worldview one can sense that the ultimate 'program' of science is to conquer the world surrounding human. As shown by Fritjof Capra (The Turning Point) this kind of philosophy of science led to environmental degradation, etc. See Figure $4 \&$ Figure 5.

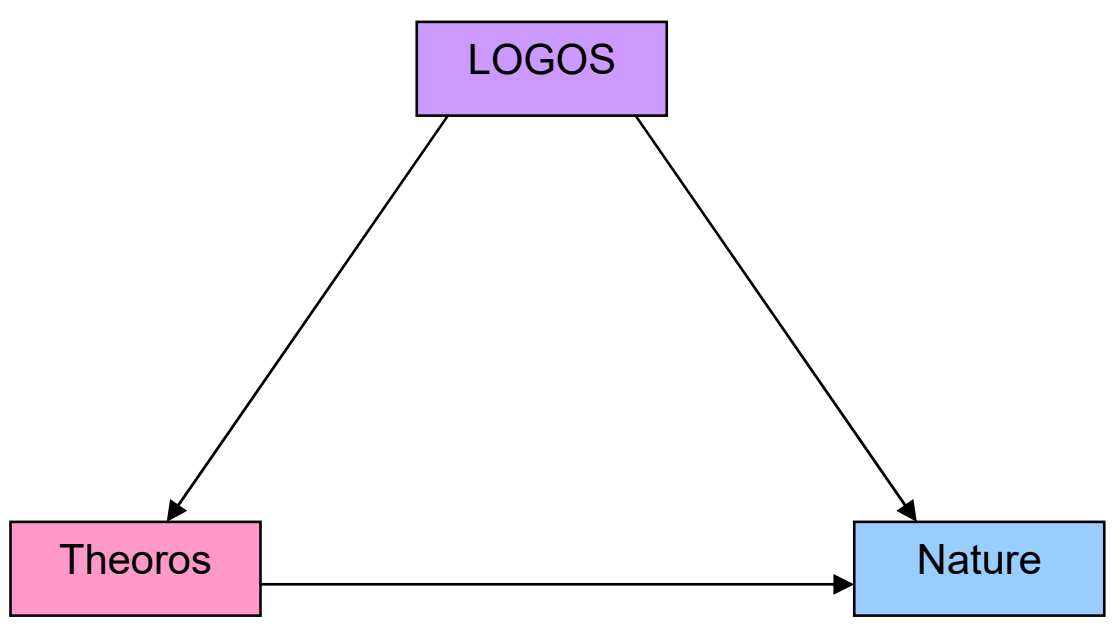

Figure 4. Scheme of method of Inquiry by Ancient Greek scholars

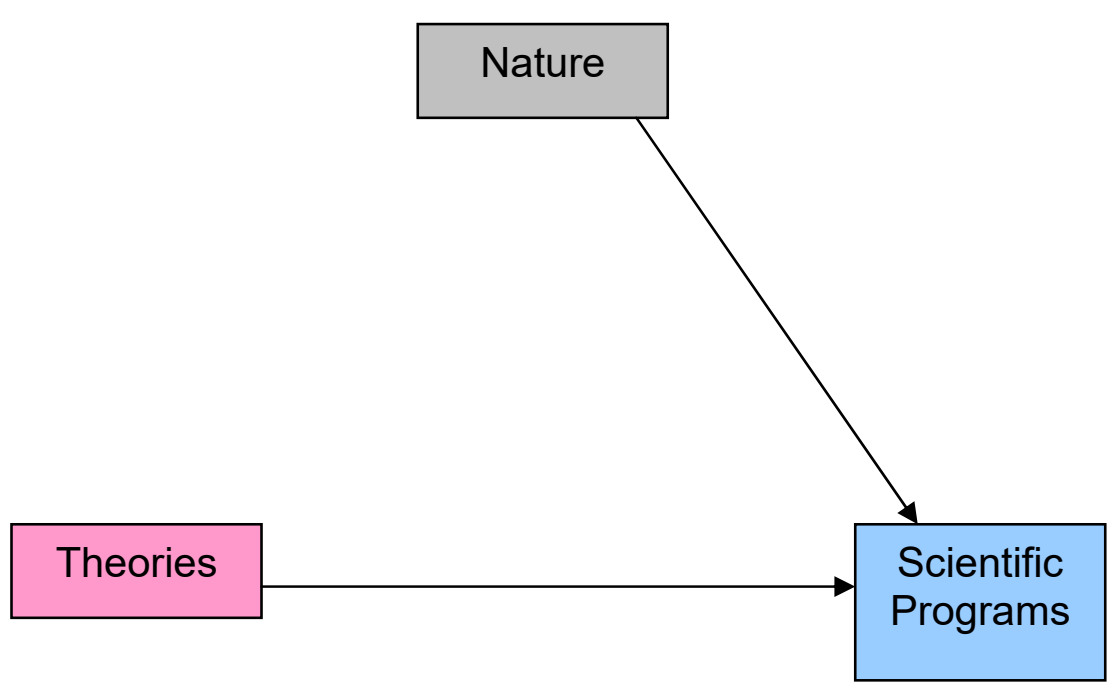


Figure 5. Scheme according to Habermas

To summarize, the methods of Inquiry in our modern times have been influenced by the so-called scientific programs. Of course, at this point one can ask whether is it possible to do research which meet the scientific programs but at the same time meet the ideals of those ancient Greek scholars? And also which is the best possible methods of Inquiry, which can lead one into a new invention or scientific discovery? As we pointed out in the beginning of this section, this question apparently belongs to the most fundamental questions for a scientist.

There are actually a few well-known methods of Inquiry, depending on one's preference:

(a) Einfuhlung: this may be a favorite method for Einstein, because he wrote that a physicist should sense something subtle in Nature before he works on the formalism itself.

(b) Generalizing Math: this method may be called as Dirac's trick, i.e. consider one equation and try to generalize its math. Thereafter you can look for its plausible implications: Does the new equation imply new physics? At least this method works for Dirac equation, and yield prediction of positron. Another example here is that one can recognize that possible breakthroughs in mathematics come from relaxing Euclid's axioms one by one, for instance by relaxing the fifth axiom (there is only one parallel through a given point to a given line) one can find geometries which go beyond flat surface: i.e. hyperbolic geometry (Lobachevsky-Bolyai-Gauss) - there are many parallels through a given point to a given line, and elliptic geometry (Riemann) - there is no parallel through a given point to a given line. Then go further and combine these geometries, since our universe is not homogeneous but heterogeneous, and consider the Smarandache's multispace, which is formed by a space which can be Euclidean and another space non-Euclidean, or even many spaces put together such that an axiom is valid in one space and invalid in various ways in other spaces (Smarandache geometries).

(c) Antithesis-Synthesis Dialectic: this method apparently is more favored by Popper, who suggests that scientific efforts move step by step nearing the hidden truth. Dialectic method was introduced by Hegel, who says that things make progress via creating antithesis and synthesis of what already exist. In other words, one should find out what others have done in a field, and then move on with something that others have not done before.

(d) Smarandache's Neutrosophic Method: this method is a generalization of Hegel's dialectic, and suggests that scientific research will progress via studying the opposite ideas and the neutral ideas related to them in order to have a bigger picture. 
(e) Music (sense of art): you may pick up violin or play flute, guitar or piano, and voilà! You discover another great thing like the next SuperDuper-General Relativity theory. Sounds a bit like exaggeration? Perhaps, but according to a study, students with musical ability tend to perceive mathematical principles better. This effect can be explained from the viewpoint that in traditional school, emphasis is given on the left side of the brain, while actually to maximize human brain's potential, one should use both sides in equal way (see also Darvas 2008).

(f) Irrelevant Fiction Stories/Books. You may have heard that Bohr likes Dickens, Einstein and others also liked fiction stories such as Sherlock Holmes. If those books are not available near you, perhaps you can begin doing permutation on random words taken from a dictionary, and find out possible meaning of their combination.

(g) Climbing or Going to Mountain: at least this method worked for Heisenberg and plenty of other physicists who sense better grasp on their problems while they were going to mountain. Some people say that going to mountain will give you a sense of unity with the entire Universe, see for example J. Redfield's book (The Celestine Prophecy). Not a bad thing to try, at least.

(h) Lateral Thinking: if you think that the traditional scientific method is a bit too methodical for you, then perhaps you can try DeBono's lateral thinking. Another way may be called as 'diagonal thinking', i.e. start with a known premise from one field of science, and then derive conclusions in other field. For example, you start with quantum principles and then derive conclusions for cosmology (i.e. quantum cosmology). Or start with antimatter/antihydrogen and find conclusions in Newtonian mechanics (e.g. is there classical antimatter?) or in Smarandache's unmatter.

And so on. See Figure 6. 


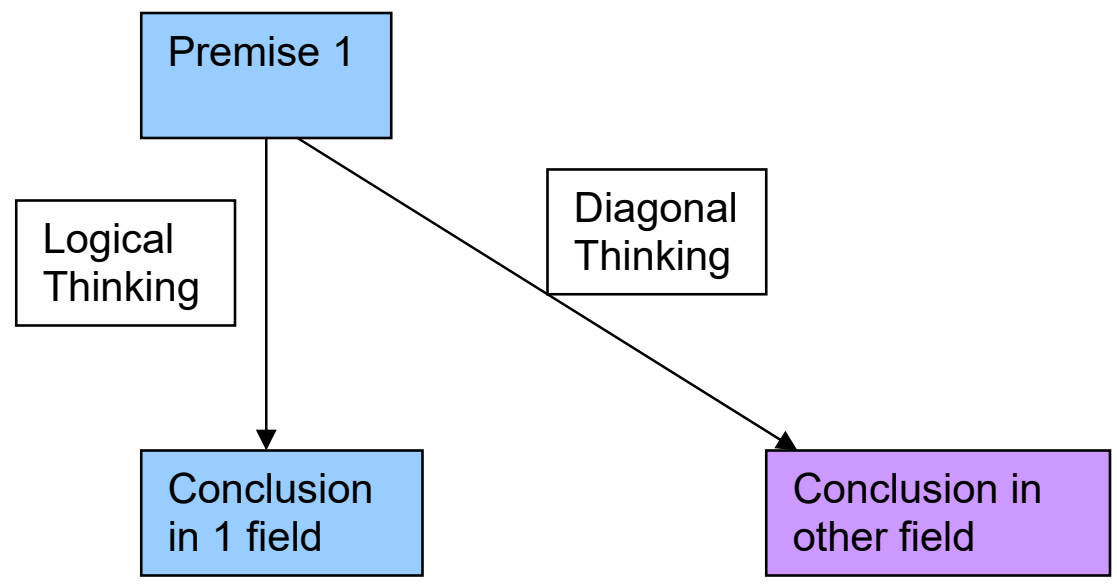

Figure 6. Scheme of diagonal thinking

If this method doesn't sound good to you, perhaps you can try to extend it a bit further, i.e. do diagonal thinking twice and you may call it 'zigzag thinking' (See Figure 7). For instance, to put quantum principles to cosmology is one thing, but you can also find relation from cosmology and particle physics, which is a very active field nowadays, called 'cosmo-particle physics'. And so on, you can also invent your own thinking way which enables you to adapt your specific abilities to your fields of interest.

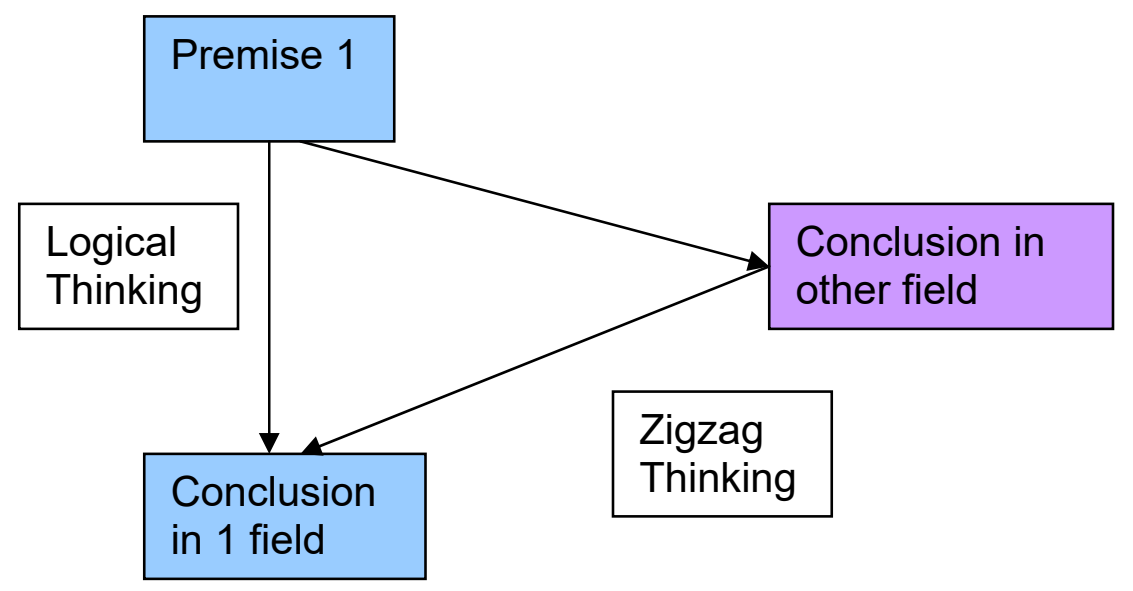

Figure 7. Scheme of zigzag thinking 
After citing some of those possible methods of Inquiry, now we're going to discuss on the relation between mathematics and symmetries behind the Nature itself.

\section{Planck and the Symmetries of Nature}

In his note on Planck, his favorite figure, Einstein wrote in 1932 (P.M. Robitaille, "Max Planck," Progress in Physics vol. 4, Oct. 2007):

"Many kinds of men devote themselves to science, and not all for the sake of science herself. There are some who come into her temple because it offers them the opportunity to display their particular talents. To this kind of men, science is a kind of sport in the practice of which they exult, just as an athlete exults in the exercise of his muscular prowess.

There is another class of men who came into the temple to make an offering of their brain pulp in the hope of securing a profitable return. These men are scientists only by the chance of some circumstance which offered itself when making a choice of career.

Should an angle of God descends and drive from the temple of science all those who belong to the categories I have mentioned, I fear the temple would be nearly emptied. But a few worshippers would still remain - some from former times and some from ours. To this latter belongs our Planck. And that is why we love him..."

According to the above very interesting remark on Planck, Einstein pointed out 3 distinctive attitudes on science which someone (or some groups of scientists) may display: sport, expected return, and true believers. If we wish to find out some parallels between this note and Habermas' viewpoint as discussed above, then perhaps it is quite appropriate to compare those interests and 'expected return' motives; and also between 'true believers' and what Habermas called as 'liberative knowledge.'

In this regards, it is also worth to mention here that Max Planck's greatest achievement, i.e. the discovery of the true statistical description of blackbody radiation is a good example on how mathematics derivation (with a fair number of premises) can lead scientists to a new and unexpected kind of knowledge.

As discussed by Darvas (2008), mathematics role in science is unavoidable, but how actually mathematics correspond to the Nature itself remains unexplainable, or in Wigner's word "unreasonable effective". In other words, we can accept the role of mathematics to describe Nature because of its effectiveness, although it is unreasonable. By doing so, of course we don't refer here to the ancient belief that Nature itself is inherently mathematical (as Pythagoras would say: "The whole thing is a number."). What we refer here is just another saying of Pythagoras: "Mathematics is the way to 
understand the Universe." (Darvas 2008) In other words, it is because simply mathematics is the only consistent and effective tool that humankind can use to analyze the world surrounding us.

By mathematics here we do not only refer to the symmetries, invariance, and transformation principles that scientists ought to use in order to find the pattern of Nature, but we can also use Wigner's definition:

"Mathematics is the science of skillful operations with concepts and rules invented just for this purpose. The principal emphasis is on the invention of concepts." (Darvas 2008, p. 10)

Or in other words we can find a somewhat simplistic description of mathematics: "A symbolic and formal formulation to express concepts." For instance, there are plenty of formulations to describe logic without introducing 'the principle of excluded middle', from Lukasiewicz, until Zadeh's fuzzy logic. Recently, a new kind of logic is developed by F. Smarandache, called 'Neutrosophic Logic', in his effort to unify the mathematical logic, statistics, and philosophy in one theoretical footing. Further implication of this new model of triple-infinite valued logic can be found in mathematical domain known as 'Information Fusion Theory' (see for example Dezert-Smarandache Theory on paradoxist information).

Therefore, apparently we can say that for the practical (pure) mathematicians, to conceive new mathematics, one does not have to care of its implications. It is task for physical sciences to think of these implications in real world. In other words, we can write the following scheme to describe how the set of mathematical theories can intersect with the set of physical theories, and also intersect with the set of observables. See Figure 8. 


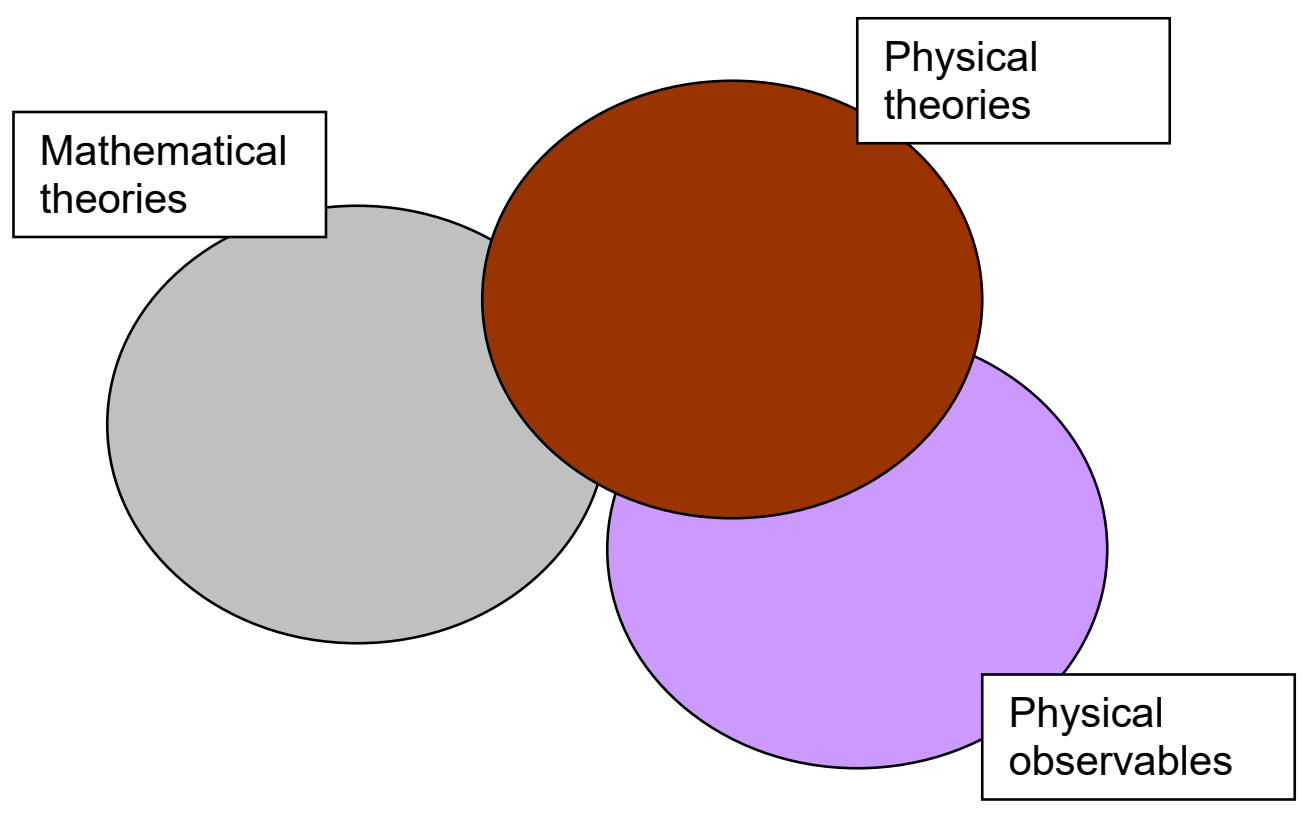

Figure 8 . The set of mathematical, physical theories, and observables

One last remark on this section is that some physicists may not agree with what we discuss above, especially those who belong or call themselves 'positivist.' For example, Hawking (arXiv:hep-th/9409195, p.1, 1994) once noted that:

"a physical theory is just a mathematical model, and it is meaningless to ask whether it corresponds to reality."

Bohr himself was also widely reputable as one of the most positivists among others, which led to his famous debate with Einstein on the interpretation of Quantum Mechanics. Einstein of course belongs to 'traditional' physicists who somehow believe that one should find out the deep physics behind Nature, that is why he sought for some kind of 'field' structure to explain the quantum effects, and therefore he considered that Quantum Theory is incomplete. (This open problem has been discussed at length in the Solvay Conference on Physics XXII held in Brussels, 2001).

However, from a viewpoint the positivists may be useful, because it should be apparent that in practice we can only speak of the physical observables (measured by some kind of apparatus setting), therefore we don't know what reality is. In particular, if we put Kant's word 'noumena' instead of 'reality', then Hawking's quote above becomes more makesense:

"a physical theory is just a mathematical model, and it is meaningless to ask whether it corresponds to noumena." 
Therefore a better scheme to represent the classic dichotomy between positivists and the so-called 'realists' is as follows (Figure 9):

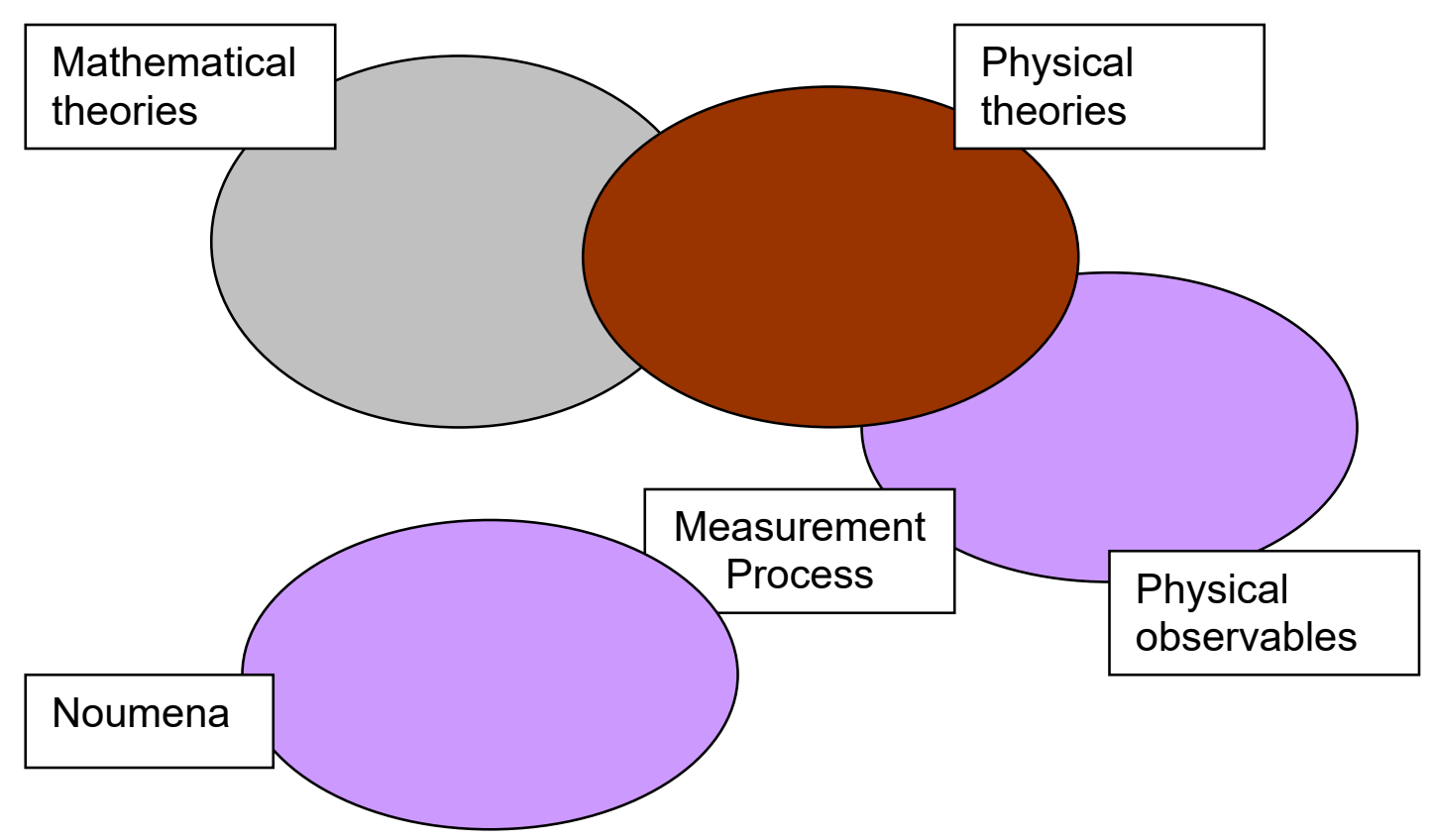

Figure 9. The set of mathematical, physical theories, and observables

From the scheme shown in Figure 6 it should be clearer why the positivists assert that one can only know (speaking of physical theories) the physical observables via measurement process, but not what Nature really is.

We can also conclude from Figure 9 that it is possible that the Noumena does not necessarily fit into our Mathematical knowledge, which seems quite a contradiction with Pythagorean's belief. (Of course, it is also possible to suppose that the set of Noumena inherently correspond to the Mathematical theories.)

\section{Extracting Knowledge from Geometry: Some possible routes}

Now if you feel some relief from reading in preceding section that at least in physical theories one can expect the 'gluing' part between mathematical ideas and physical observables, you will never know how physical theories can become so weird, depending on the mathematical notions where they have started from.

For example, one common problem in physical sciences is how to 'extract' knowledge in geometry, for instance a planet's motion or trajectory of satellites. And a fundamental 
mathematical concept behind this geometry is the definition of 'distance.' For the beginners, traditionally we use the Cartesian coordinates as follows:

$$
d s^{2}=d x^{2}+d y^{2}+d z^{2}
$$

But then physicists began to include time as the fourth component of the metric, to become Minkowski metric:

$$
d s^{2}=d x^{2}+d y^{2}+d z^{2}-c^{2} \cdot d t^{2}
$$

which is known as the basis of the Special Relativity theory (1905). In the meantime, General Relativity theory uses the non-flat metric with constant curvature, which was introduced by Gauss, Riemann etc.:

$$
g=g_{a b} \cdot d x_{a} \otimes d x^{b}
$$

By virtue of the equivalence principle, this pseudo-Riemann metric with constant curvature corresponds to the gravitation phenomena.

While it's instructive to study this pseudo-Riemann metric in order to understand the General Relativity theory, one can consider another dimension(s) to become 5-dimensional or 6-dimensional metrics and so on. There are also some new theories with extra-dimensions, including higher-dimensional gravities, multidimensional gravity theories, and also Smarandache's multispace theories.

This kind of metrics with extra-dimension(s) has become so advanced in the so-called superstring theories, where the most recent theory is so-called 26-dimensional Bosonic string.

It is less mentioned in literature that Riemann himself in one of his talk did make a deliberate remark, mentioning that even the concept of distance and metric are merely construction of human mind. He also suggested possibility to study metric where the metric interval is expressed as the fourth exponent of the distance, i.e. for Minkowski metric it can be written:

$$
d s=\sqrt[4]{d x^{4}+d y^{4}+d z^{4}+(i c \cdot d t)^{4}} .
$$

While this metric looks quite awkward, it may be useful for studying gravitation theories, in particular in the context of generalization of pseudo-Riemann metric, for example using the Finsler geometries (e.g. the so-called Berwald-Moor metric), or Smarandache geometries endowed with semi-metrics. (Rabounski, 2010 [9])

It is worth to note here, that one can also consider an extra dimension to Minkowski metric in terms of velocity component, so the metric becomes: 


$$
d s^{2}=d x^{2}+d y^{2}+d z^{2}-c^{2} \cdot d t^{2}-\tau^{2} \cdot d v^{2}
$$

Which is the so-called Carmeli metric, and the velocity component corresponds to the galaxy's velocity.

Now, it is possible to find out the symmetries, invariance, and transformation laws corresponding to the above (1)-(5) metrics, and also to figure out their implications to the physical world. Symmetry itself can be defined as "invariance with respect to a transformation group" (Esposito \& Marmo, 2005).

Another way is to introduce the Hausdorff dimension into the metric, which one allows to consider non-integer dimension. This seems to correspond to the fact that this Earth and other planetary surfaces are far from smooth; therefore the metric of smooth surface is only an approximation. The problem then is how to express the differential geometry principles for this non-smooth metric. Now we face quite a paradox because a surface with Hausdorff non-integer dimension can be non-differentiable or non-integrable, just like Weirstrass function. Then how can one define differential geometry for nondifferentiable surfaces? A particularly noteworthy example in this regards is perhaps Nottale's Scale Relativity Theory which defines differentiation on such nondifferentiable geometry. Another model of universe based on the non-integrable geometry has been presented by Maciejewski et al. (2002), while Ronchetti \& de Sabbata (2002) discussed a quantum gravity model based on the notion of Hausdorff dimension. These novel approaches are mentioned here as mere examples on how different theories can emerge from different assumption of the non-smooth geometry.

At this point, perhaps it is not appropriate to speak of mathematics as the inherent properties of Nature anymore (as Pythagoreans would say), we can only guess what is the most consistent geometry corresponding to a given set of Natural phenomena (known to these days). We can only guess it and hopefully will find the true geometrical structure of Nature, possibly via studying the most generalized type of the metric.

The same principles apparently also apply to the physics of elementary particles or bioinformatics. Without reiterating here what Darvas (2008) has described, especially concerning the role of complex numbers in describing codon, or C. M.Yang's method using quasi-28-gon, one can note that in elementary particles or bioinformatics, the role of metric in standard physics has been replaced with the 'symmetry principles' of certain groups.

And with respect to the group theories, then it appears that these symmetry principles can be used to extract new knowledge, just as the role that symmetry consideration may have played during formulation of Newton's equations or Maxwell's equations (Darvas 2008).

Nonetheless, there are other types of governing dynamics, for instance the spontaneous symmetry breaking, which can lead to another type or new symmetry principle. How exactly this approach will affect our perception of bioinformatics or the structure of life 
itself, remains an open question. For example, does life come from some phenomena related to the spontaneous symmetry breaking of some chemical compounds?

\section{Concluding Note}

We have shortly discuss in this article, how scientists including physicists, mathematicians and bioinformatics specialists etc., rely on some special properties in mathematics (via symmetries, transformation and invariance principles) to reveal new kinds of knowledge. These properties are supposed to be able to give some clues of the dynamics of the Nature (or better perhaps, of the dynamics of some given observable phenomena).

Nonetheless, as with the choice of the groups or the metric to be used, it remains an open question to the scientists themselves. In this regard, one should not force his/her own conception to the Nature. Instead, one can begin to learn and respect the Nature.

Concerning how far the contradiction between these approaches can be, one can rephrase an old saying reflecting the (quite antagonistic) Baconian world view: "If you torture the data long enough, Nature will confess." The modern version of the same 'attitude' toward Nature perhaps can be written: "If you torture geometry long enough, Nature will confess."

Returning to the Einstein's note on Plank as cited above, the somewhat protagonist view of scientists would learn from Nature and seek to understand it, instead of just forcing Nature to "behave" just as what he/she commend. In other words, apparently it would be better if the physical explanation can be extracted directly from the metric itself plus some new concepts, instead of retaining the same concept but having to "torture" the geometry. In this sense, perhaps one can understand why the General Relativity theory is so fascinating, because it just reinterprets the pseudo-Riemann metric and gives it new physical meaning.

Kaluza-Klein theory also remains beautiful because it only introduces minimal modification to GTR, by including a fifth-component into the metric. But at this point, we don't want to make early remark on other modern theories including supersymmetry, string theories, etc.

Last but not least, by making this quite strong wording on 'torture' of geometry, of course we do not mean that only a handful of approaches are plausible, and other theories shall be forbidden. With regards to mathematical theories, one is free to conceive any kind of idea he/she had, nonetheless at the same time when one develops physical theories, it should be better if they can explain or predict some phenomena where the theories can be put compared with observation. Or if we are allowed to quote what Prof. Gell-Mann once remarked: physicists should find a balance between abstraction and phenomena, just like in Odyssey story one should sail between Scylla and Charibdis. 
As for this end of this article, allow me to repeat here a great wisdom saying: May the force be with you.

\section{Acknowledgement}

Special thanks to Prof. V.V. Kassandrov for informing Darvas' (2008) presentation.

(Version 1, 21 Feb. 2009. Revised 2 ${ }^{\text {nd }}: 23$ Feb. 2009, Revised $3^{\text {rd }}: 14$ March 2009, Revised $4^{\text {st }}: 20 \mathrm{Feb} .2010$.)

\section{References}

[1] Berlinsky, D., Infinite Ascent (2005).

[2] Capra, F., The Turning Point (1996).

[3] Darvas, G., "The unreasonable effectiveness of symmetry in the sciences," Invited paper to the workshop Measuring Biology, Sept. 2008 (2008). See also journal Symmetry: Culture and Science.

[4] Esposito, G., "Highlights of symmetry groups," arXiv:math-ph/0511063 (2005) p.2

[5] Gholson, B., \& P. Barker, "Kuhn, Lakatos, Laudan: application in the history of physics and psychology," American Psychologist (July 1985) 755-770.

[6] Maciejewski, A.J., M. Przybylska, \& M. Szydlowski, "Living in the non-integrable universe,"Grav. \& Cosmol. Vol. 8 Supplement II (2002) p. 93-99.

[7] Ronchetti, L., \& V. de Sabbata, "Quantum gravity theory with torsion and spin fluctuations," Grav. \& Cosmol. Vol. 8 no.3(31) (2002) p. 175-180.

[8] Wigner, E.P., "Symmetry and Conservation Laws," PNAS, vol. 51 no. 5 (1964) http://www.pnas.org.

[9] Rabounski, D., Smarandache Spaces as a New Extension of the Basic Space-Time of General Relativity, Progress in Physics, Vol. 2, L1-L2, 2010. 


\section{Clan Capitalism, Graph Distance and other issues}

A collection of social and economics papers

\section{Abstract}

This book consists of 6 papers focusing on social and economic issues. The topics covered include graph distance and optimal communication, migration in Jaipur, urbanization, clan capitalism, world population growth rate, and scientific inquiry. These papers were written in the period between 2009-2010. Hopefully the readers will find some new insights in this collection of papers.

Disadvantage of excessive liberalization
Oligopoly risk
Clan groups will pay incentive to their
clan associate in democracy institutions

Clan groups pay less tax rate

Reduce benefits for common people

Hidden opportunity cost

\section{Description}

There is tendency that clan groups will form oligopoly if there is not anti-trust or anticlan law enacted.

There is tendency that those clan groups or their oligopolistic association are more willing to pay more to their 'associates' in democracy institutions included law enforcement agencies in order they can continue their clandestine operations. Such practice is often found in a number of countries. This practice cannot be stopped without introducing special regulation. There is tendency that such oligopoly associations and clan groups expect a sort of benefits from influencing democracy institutions, especially tax collecting agents and law enforcement agencies, that is benefits in the form of lower tax rates, compared to what they actually ought to pay. Member of those clan groups expect that discounted tax rate as their benefit. In practice, excessive liberalization would mean less regulation, but that often would mean benefit only for larger clan groups. And common people will receive less benefit, especially because large clan groups will affect both market and democracy institutions alike to their advantages. Clan groups often play their role as middlemen and intermediaries who stay in the middle of a number of transactions type, including negotiation of certain projects, those practices can be found in number of countries including Japan, for example. 